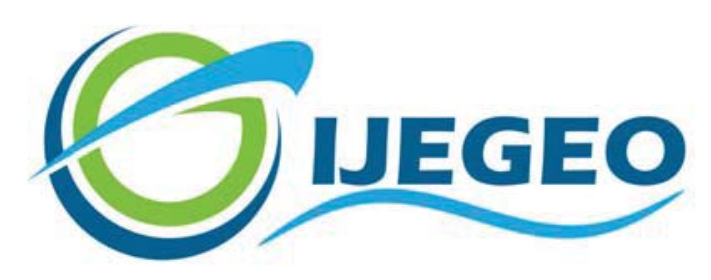

International Journal of Environment and Geoinformatics (IJEGEO) is an international, multidisciplinary, peer reviewed, open access journal.

\title{
Preliminary application of space-based remote sensing and geospatial technology for investigation on the geo-environmental consequences of Cyclone Aila 2009 in the SW Bangladesh
}

\section{Farhana TAZNEEN, Hafizur RAHMAN, Sajidur RAHMAN, Nasrin SULTANA, B.M. Refat FAISAL}

\author{
Chief in Editor \\ Prof. Dr. Cem Gazioğlu \\ Co-Editors Prof. Dr. Dursun Zafer Şeker, Prof. Dr. Şinasi Kaya, \\ Prof. Dr. Ayşegül Tanık and Assist. Prof. Dr. Volkan Demir
}

Editorial Committee (June 2022)

Assoc. Prof. Dr. Abdullah Aksu (TR), Assoc. Prof. Dr. Uğur Algancı (TR), Assoc. Prof. Dr. Aslı Aslan (US), Prof. Dr. Levent Bat (TR), Prof. Dr. Paul Bates (UK), İrşad Bayırhan (TR), Prof. Dr. Bülent

Bayram (TR), Prof. Dr. Luis M. Botana (ES), Prof. Dr. Nuray Çağlar (TR), Prof. Dr. Sukanta Dash (IN), Dr. Soofia T.

Elias (UK), Prof. Dr. A. Evren Erginal (TR), Assoc. Prof. Dr. Cüneyt Erenoğlu (TR), Dr. Dieter Fritsch (DE), Prof.

Dr. Ç; Prof. Dr. Manik Kalubarme (IN), Dr. Hakan Kaya (TR), Assist. Prof. Dr. Serkan Kükrer (TR), Assoc. Prof. Dr.

Maged Marghany (MY); Prof. Dr. Micheal Meadows (ZA), Prof. Dr. Nebiye Musaoğlu (TR), Prof. Dr. Masafumi

Nakagawa (JP), Prof. Dr. Hasan Özdemir (TR), Prof. Dr. Chyssy Potsiou (GR), Prof. Dr. Erol Sarı (TR), Prof. Dr.

Maria Paradiso (IT), Prof. Dr. Petros Patias (GR), Prof. Dr. Elif Sertel (TR), Prof. Dr. Nüket Sivri (TR), Prof. Dr. Füsun

Balık Şanlı (TR), Dr. Duygu Ülker (TR), Prof. Dr. Seyfettin Tsaş (TR), Assoc. Prof. Dr. Ömer Suat Taşkın (TR), Assist. Prof. Dr. Tuba Ünsal (TR), Assist. Prof. Dr. Sibel Zeki (TR) 


\title{
Preliminary application of space-based remote sensing and geospatial technology for investigation on the geo-environmental consequences of Cyclone Aila 2009 in the SW Bangladesh
}

\author{
Farhana Tazneen ${ }^{1}$ Hafizur Rahman ${ }^{1}$ (i) , Sajidur Rahman ${ }^{(D)}$, Nasrin Sultana ${ }^{1}$, B.M. Refat \\ Faisal $^{1}$ iD
}

${ }^{1}$ Bangladesh Space Research and Remote Sensing Organization (SPARRSO), Agargaon, Shere Bangla Nagar, Dhaka-1207, BANGLADESH

${ }^{2}$ Centre for Climate Change and Environmental Research (C3ER), BRAC University, 66 Mohakhali Dhaka 1212. BANGLADESH

How to cite: Tazneen et al. (2022). Preliminary application of space-based remote sensing and geospatial technology for investigation on the geo-environmental effects of Cyclone Aila 2009 in the NW Bangladesh. International Journal of Environment and Geoinformatics (IJEGEO), 9(2):120-138, doi10.30897/ijegeo.838241

\begin{abstract}
Climate change phenomena have become a great concern in the context of global change and increased frequency and magnitude of natural disasters throughout the world in the recent time. Natural disasters like floods, cyclones, storm surges etc. often cause significant losses of life, large-scale economic and social impacts, and considerable environmental damages. This paper dealt with study on the overall methodological development to investigate the consequences of climate change extremities particularly, the after effects of cyclone using Remote Sensing (RS) and Geographic Information System (GIS) technology. In this connection, individual functional components have been investigated, tested and verified. Time series multi-sensor satellite data particularly of Landsat, World view (from Google origin) have been utilized to infer information on the consequences of Cyclone Aila 2009 hitting part of southwestern Bangladesh as a test case under the present study. Information retrieval mechanism utilized is based on specially designed methodological framework using satellite-based RS technology along with GIS. Developed technical approach consists of a three-fold components - (i) Establishment of input foundation layer with high spatial details to support characterization, recognition and identification of important surface features using high resolution satellite data; (ii) Effective operational procedure to process, analyze, interpret and finally to archive the retrieved information; (iii) Functional computations were made using spatial modeler language (SML) programming environment under ERDAS Imagine image processing software. Satellite image processing, analysis operation together with image-based spectral characterization of surface features under different stressing conditions etc. have been exercised to derive useful surface information. Specially designed geospatial database has been established in GIS using ArcInfo professional software. Varieties of geospatial data from diverse sources have been incorporated categorically as column-based attributes in GIS. Dual spatial data layers have been generated in GIS for two different dates representing the pre-cyclone and postcyclone time sequences utilizing appropriate high spatial resolution satellite images. Finally, a geospatial image-based combinational technique has been utilized employing high temporal and moderate spatial resolution time series satellite data with low temporal and high spatial resolution satellite data. Such an operation results in an improved spatial and temporal resolution of output products enabling capture of dynamics of surface features in the spatiotemporal domain providing more precision and details in the output. This study has been supplemented with necessary Ground Position System (GPS)-based ground truthing, selected field data collection and field-based group discussions outcomes.
\end{abstract}

Keywords: Geospatial techniques, GIS, Remote sensing, Landsat, Disaster.

\section{Introduction}

Bangladesh is one of the largest deltas in the world which is highly vulnerable to natural disasters due to its unique geographical location, flat and low-lying landscape, population density, poverty, illiteracy, lack of institutional setup etc (Sultana et al., 2019; Rahman and Rahman, 2022). The coastal areas of Bangladesh are particularly disaster prone because of their geographical location, land characteristics and the proximity to the funnel-shaped feature (which reduces the width and increases the height of storm induced waves) of the northern Bay of Bengal (UNEP, 2001). This coastal zone forms the lowest landmass (in cases 0-30 cm Mean Sea Level), part of a delta of the extended Himalayan drainage ecosystem, and is exceedingly prone to multiple threats like cyclones, storm surges, floods, tsunamis, and climate change (Bishawjit et al., 2017). The coastal zone is identified as an "agro-ecologically disadvantaged region" by the government (GoB, 2005). The dense population in Bangladesh results in a high human-toland ratio of about 520 people per square kilometer (BBS, 2012a). This high density has a significant influence on land use/land cover. According to the LongTerm Climate Risk Index (CRI) 2017 of German watch, Bangladesh has been identified as the top sixth most affected country in the period 1996-2015 in the world due to climatic disasters (Kreft et al., 2016). All the adverse effects have aggravated the overall economic development scenario of the country to a great extent. The combined effect of natural and anthropogenic activities together further intensifies the damage to the 
ecosystem and hampers the economy, livelihood, migration (Rowsell et al., 2013) and development of the coastal areas of Bangladesh (MWR, 2005). Planning to mitigate the impact of such incidents has become even more critical, given the prediction of increased climatic extremes associated with an "enhanced greenhouse effect." UN stressed the need for special attention to be given to planning ahead for natural disasters and to reducing long-term vulnerability in those countries at highest risk.

It is quite obvious that space technology inputs are crucial for disaster monitoring, management etc. as it is the only means to obtain needed real-time data in remote and inaccessible areas. Recent advancements in remote sensing and its application technologies made it possible to use remotely sensed imagery data for assessing vulnerability of urban areas and for capturing damage distribution due to natural disasters (Menteş et al., 2019; Shinozuka and Rejaie, 2000). Remote sensing (RS) imagery derived from airborne (suborbital) digital and earth observation satellite (orbital) systems (Visser and Darwood, 2004) provide valuable sources of information about the location and severity of damage following major disasters (Stryker and Jones, 2009). The techniques of GIS and satellite remote sensing had been widely applied on detecting land use /land cover changes (Li and Yeh, 1998; Lopez and Bocco, 2001; Prenzel, 2004).

Integrated GIS and remote sensing technology constitute a useful and effective tool in disaster monitoring and management operation. These technologies have been the object of substantial interest for all countries and bodies concerned with space and in exacting emergency services and disaster management. In disaster management, the objectives of the disaster experts are to monitor the situation, simulate the complicated disaster occurrence as accurately as possible so as to come up with better prediction models, suggest appropriate contingency plans and prepare spatial databases. Remotely sensed data can be used very effectively for quickly assessing severity and impact of damage due to, earthquakes, landslides, flooding, forest fires, cyclones and other disasters (Sharma et al., 2010).

When both pre-disaster and post-disaster data are available, optical data can be used to detect changes. A good number of methodologies is presently available that could be used to extract damage on a pixel-by-pixel basis from optical images, depending on the resolution and the time difference between the images. Moreover, spectral as well as spatial (e.g. textural) features may be considered as input to the selected change detection method. Final damage detection and evaluation is done at some object level (buildings or blocks), the analysis can be directly obtained at the object level or is first performed at the pixel level, and the results are jointly considered within a spatially defined area.

A GIS has a graphic database of geo-referenced information system, which is linked to the descriptive database. It uses high-powered graphic and processing tools that are equipped with procedures and applications for inputting, storing, analyzing and visualizing georeferenced information. Various disasters like cyclones, floods, earthquakes, tsunamis and other natural hazards very often cause significant losses of human lives, their properties and infrastructures. Remotely sensed data can be used to assess the impact of damages due to these disasters. In the disaster relief phase, GIS, grouped with global positioning system (GPS) is extremely useful in search and rescue operations in areas that have been devastated and where it is difficult to find one's bearings.

This research examines the use of RS technologies for damage assessment in disasters and presents a framework for the application of remote-sensing technologies specifically to the disaster. Modern remotesensing technologies, including high-resolution satellite imagery, have proven effective for study of damage caused by multiple hazards such as cyclones. Ongoing developments in the fields of remote sensing and digital image processing can eventually lead to the computerautomated detection of disaster related damages. Space technology has significant influence in the decisionmaking processes in almost all social spheres. It encompasses information generation on natural resource viz., land use, agriculture, climate, urban systems for better management of resources and in protecting ourselves from the impact of natural calamities like cyclone, flood, drought, forest fire and landslide etc. by being informed about the probability of occurrence and preparing contingency to face it.

The goal of this research is to provide a comprehensive perspective on the rationale and end-to-end design of time-sensitive remote sensing systems (TSRSS) that are able to provide timely information on extent of damage and volume of debris immediately following hazard events in support of decision making by emergency managers.

This research focuses on the region hit by Cyclone Aila, covering the Khulna and Satkhira district. Both was inundated and heavily damaged by Cyclone Aila. This study demonstrated the capability of a remote sensing approach for assessing multiple damages produced by the cyclone using object-based classification from multisensor images. Multi-date images have been utilized for mapping pre- and post-cyclone land covers in the study area with a high degree of accuracy and indicated the usefulness of object-based approach.

This study has been carried out with the following objectives:

i) Application of remote sensing technology for inferring biophysical information over the present study area.

ii) Preparation of spatial database in GIS with relevant surface parameters as retrieved through.

iii) Analysis of time series multi-sensor satellite images of different resolutions to study the land use and land cover changes under pre and post Aila scenarios.

iv) Characterize the changes due to cyclone Aila. 


\section{Materials and Method Study area}

The study area includes part of the coastal region situated in the southern side of Bangladesh as shown in figure 1 . The study concentrates on six upazilas of two districts of country. Koyra, Dacope and Paikcachha upazila are under Khulna district. Tala, Assasuni and Shamnagar upazila are under Satkhira district. Study area is located between $21^{\circ} 37^{\prime} 54.99^{\prime \prime}$ and $22^{\circ} 17^{\prime} 24.80^{\prime \prime}$ north latitudes and between $89^{\circ} 38^{\prime} 1.55^{\prime \prime}$ and $88^{\circ} 59^{\prime} 37.14^{\prime \prime}$ east longitudes. The breakup of the study area falling under different administrative units is given in following Table 1.

Table 1: Upazila wise area and population under the study area.

$\begin{array}{ccrc}\text { District } & \text { Upazila } & \begin{array}{c}\text { Area } \\ (\text { Sq. km. })\end{array} & \text { Population } \\ & \text { Dacope } & 992 & 152316 \\ \text { Khulna } & \text { Koyra } & 1,775 & 193931 \\ & \text { Paikgachha } & 411 & 247983 \\ & \text { Assasuni } & 375 & 268754 \\ \text { Satkhira } & \text { Shyamnagar } & 1,968 & 318254 \\ & \text { Tala } & 337 & 299820\end{array}$

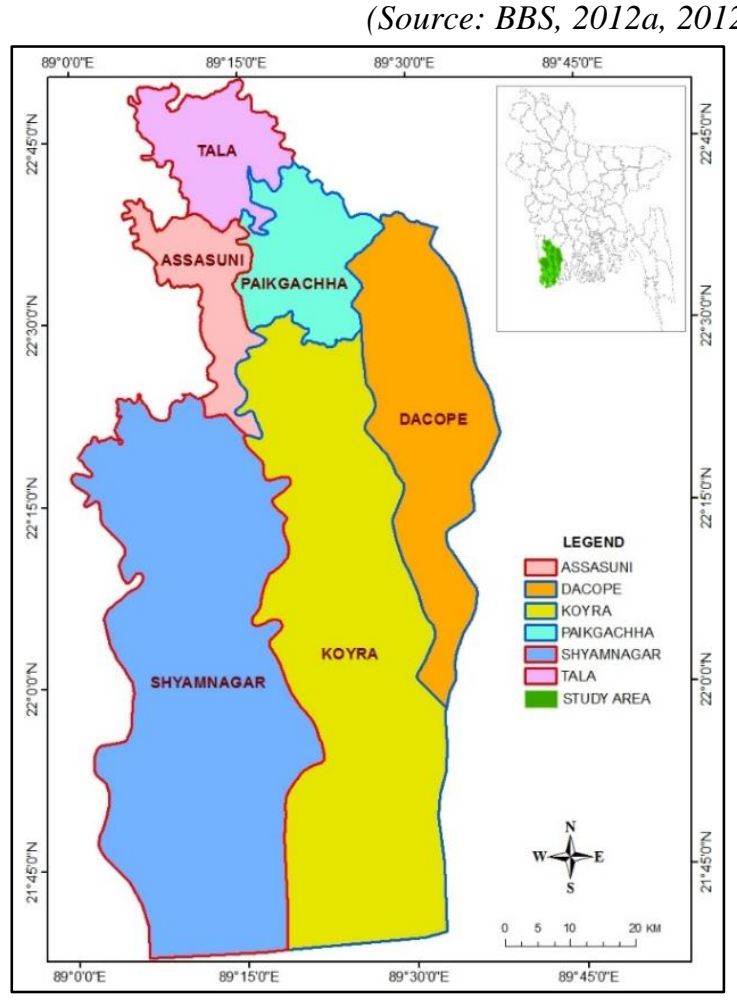

Fig. 1. Study area covering six upazilas under Khulna and Satkhira District.

About 1481058 people live in these six upazilas (BBS, 2012a, b). The study area is located in Ganges Tidal Plain or the Western Coastal Region of Bangladesh coast (Islam, 2001).

The study area has tropical monsoon climate like whole area of the country. Three seasons summer, rainy and winter are generally observed over this region. The rainy season extends from May to October, the winter season extends from November to February and the summer extends from March to April. Maximum rainfall is recorded in rainy season, and the maximum temperature observed in summer season.

Natural disasters such as cyclones, storm surges, tidal floods, saline water intrusion and water logging are prominent features of this area. In addition, land-use and land-cover change is another major concern. The humaninduced shrimp farming initiates salinity that seriously affects agricultural production and makes the region vulnerable to unsafe drinking water.

The magnitude, as well as frequency of disasters has been increasing in recent years. Natural disasters, such as cyclone, foods, drought, landslides and desertification etc. often cause significant losses of lives and properties of the people. There has been a global concern to undertake effective actions in reducing and mitigating the impacts of disasters through appropriate disaster management procedure. The General Assembly of the United Nations in 1987 designated the 1990s as the International Decade for Natural Disaster Reduction (IDNDR) with Secretariat in Geneva, Switzerland. Any remote sensing-based decision support system should be first and foremost, responsive to users' information requirements (Phinn, 1998). Information requirements of emergency response organizations need to be specified, in order to develop a Time-Sensitive Remote Sensing Systems (TSRSS) that provides appropriate information in a sufficiently reliable and timely fashion.

\section{Data Used}

Table 2 provides a list of the satellite data used in the present study. The list includes satellite Landsat 5 Thematic Mapper of 2008, 2009 and 2010 along with Google image of 2001, 2008 and 2011 have been analyzed specifically to study geo-environmental consequences of cyclone Aila in the area under investigation. Landsat TM has a spatial resolution of 30 $\mathrm{m}$. The satellite data were obtained from Earth explorer site (http://earthexplorer.usgs.gov/) and Google images from Google Earth (Table 2).

Table 2: Specification of Satellite Data.

\begin{tabular}{|c|c|c|c|c|}
\hline Satellite & Sensor & Path/ Row & Acquisition Date & Resolution \\
\hline Landsat 4-5 & $\mathrm{TM}$ & $138 / 44$ & $\begin{array}{r}\text { October 30, } 2008 \\
\text { February 3, } 2009 \\
\text { May 10, } 2009 \\
\text { June 11, } 2009 \\
\text { October 17, } 2009 \\
\text { February 6, } 2010\end{array}$ & $30 \mathrm{M}$ \\
\hline Google Image & - & $138 / 45$ & $\begin{array}{r}\text { February 19, } 2009 \\
\text { January 25, } 2001 \\
\text { November 27, } 2008 \\
\text { March 01, } 2010 \\
\text { February 11, } 2011\end{array}$ & - \\
\hline
\end{tabular}




\section{Methodology}

To fulfill the aims and objectives of this research work ERDAS Imagine and ArcGIS software were used for extracting landuse/cover data of different periods. Figure 2 shows the overall methodological steps as adapted to implement various tasks under the present study theme.
The study area was extracted from satellite images by using vector GIS boundary layer. Digital interpretation has been made out to identify the surface features over the study area. Thematic data layers were generated following the procedural flowchart as provided in Fig. 2. of the overall working methodology of the present work.

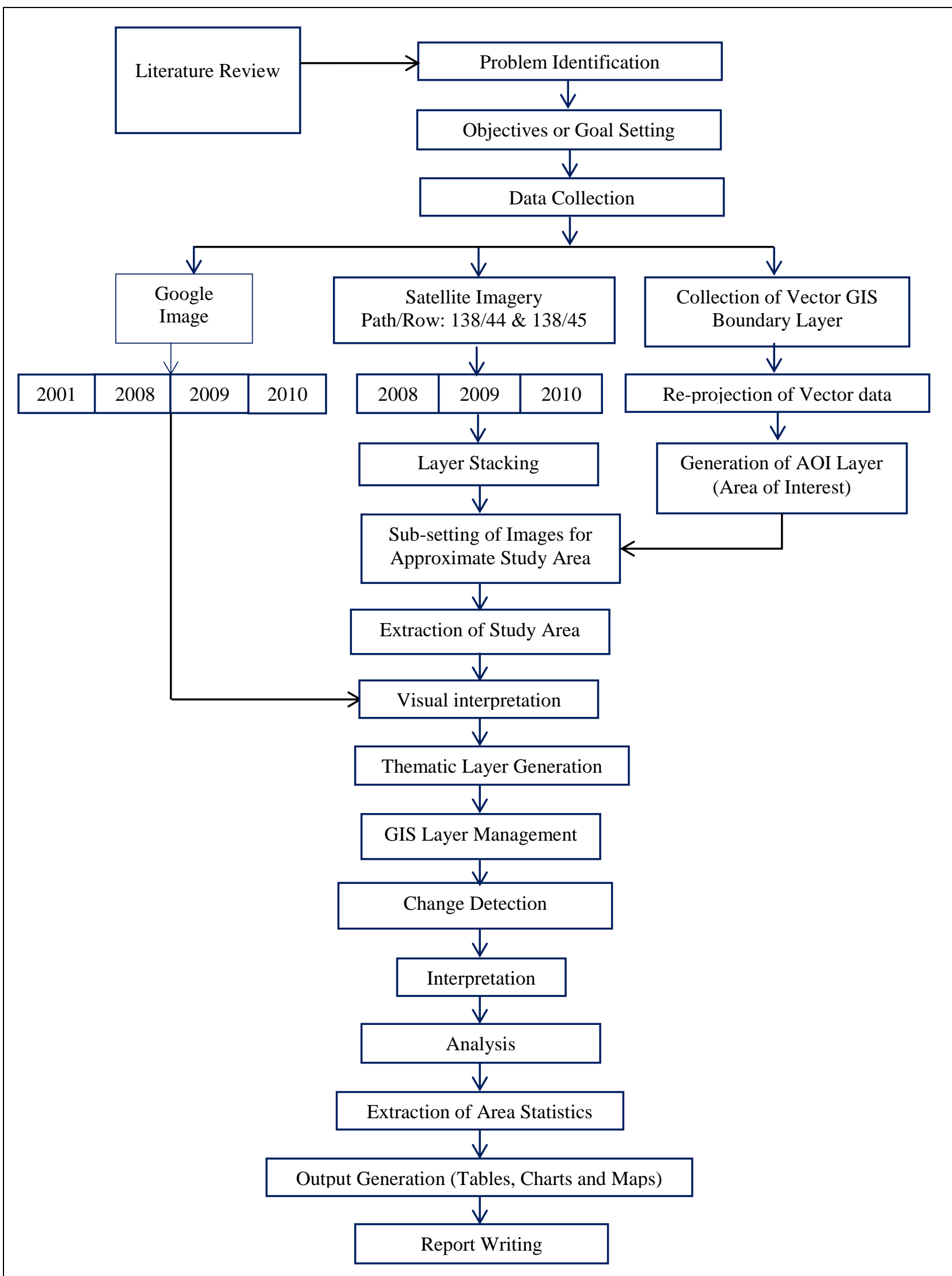

Fig. 2. Flow chart of the working methodology under the present work. 


\section{Data Processing, Analysis, Interpretation and Classification}

Landsat TM images were formatted into ERDAS Imaging IMG format. DN values were transformed into reflectance values. Necessary atmospheric corrections have been made utilizing Simplified Method for Atmospheric Correction (SMAC) of satellite images (Rahman and Dedieu, 1994) to normalize the differences in radiative values of surface features between images acquired under different dates under different atmospheric conditions. Corrections have been performed for scattering due to atmospheric aerosols and molecules. Post-processing of the images has been carried out following ---- techniques in the ERDAS Imagine image processing software supported with ArcInfo GIS.

\section{Change Detection and Damage Assessment}

Integration of GIS and remote sensing technologies have been the object of substantial interest in producing and providing emergency services supporting disaster management (Mas, 1999) initiatives. Remotely sensed data have proven to be very effective for rapid assessment of severity and in analyzing damaging impacts due to cyclones and other disasters (Ali et al., 1998; Rahman, 1999). Timely and accurate change detection of Earth's surface features is extremely important for understanding relationships and interactions between human and natural phenomena in order to promote better decision making. Many change detection techniques have been developed ( $(\mathrm{Lu}$ et al., 2004). Different change detection algorithms have their own merits and no single approach is optimal and applicable to all cases. In practice, different algorithms are often compared to find the best change detection results for a specific application.

Change detection using both pre- and post-disaster remote sensing data is one of the most commonly used methods for damage assessment. Change detection approach detect the differences in the state of a landsurface before and after a disaster event using pre- and post-disaster images. All the geospatial data layers including satellite images of pre- and post-disaster event must have the same geometry and wavelength, and have to be well co-registered. Change detection can be implemented by using shape analysis, brightness value comparison, image differencing etc. The differences between color, spectra, texture, and other features extracted from the registered images can also be used to discriminate surface features under the category of damaged and undamaged object classes.

In general, digital change detection methods are divided into pre-classification spectral change detection or postclassification change detection methods (Nelson, 1983; Pilon et al., 1988). Under post-classification change detection approach, two images acquired on different dates are separately classified, and the changes are identified through the direct comparison of the classified information (Howarth and Wickware, 1981). Spectral change detection approach under pre-classification techniques rely on the principle that land cover changes result in persistent changes in the spectral signatures of the affected land surfaces. These techniques involve the transformation of two original images into a new singleband or multi-band image in which the areas of spectral changes are highlighted (Yuan et al., 1998).

Digital processing, analysis and interpretation for images of pre- and post-cyclone time sequences were carried out based on standard technique of colour and texture analysis for particular colour composite $\mathrm{R}$ (Near Infrared), G (Red) and B (Green) of the image. Thematic data layers were generated from the images of study years using unsupervised classification of the images. The thematic data layers were generated in vector format. ERDAS imagine software was used for generation of thematic data layers. For GIS analysis the vector data layers were managed in suitable form and generate statistics of changes of the study area, as well as to generate the relevant map product. Under the present research work, a total five landuse/cover types have been identified in the study area, these are: barren land, crop, water, vegetation and other (Table 3).

A convenient way to assess the post classification dynamics is identifying the change based on change statistics. ArcGIS analysis tool was used to portray the dynamics of land cover change that have taken place after cyclone Aila. The tool measures the transition dynamics of a land cover class to another class at a given extent. Total 9 unique classes were introduced as a change factor between the two-time span. At the final stage two distinct output file was created from which the first one is change vector file (Figure 2) and the final output consist of change statistics (Table 6). Finally, the resulting information was analyzed to assess the impacts of extreme events on the study area.

Table 3: Landuse/Cover Types

\begin{tabular}{ll}
\multicolumn{1}{c}{$\begin{array}{c}\text { Landuse/ } \\
\text { cover types }\end{array}$} & \multicolumn{1}{c}{ Description } \\
\hline Barren Land & Unused empty dry soil \\
Crop & Crop field \\
& $\begin{array}{l}\text { River, permanent open water, perennial lakes } \\
\text { and reservoirs, semi-inundated land filled } \\
\text { with marshy vegetation }\end{array}$ \\
Water & $\begin{array}{l}\text { vegetation, trees, shrub lands, natural and } \\
\text { manmade forest }\end{array}$ \\
Vegetation & Unused empty wet soil etc. \\
\hline
\end{tabular}

The temporal change detection map has been prepared from two Landsat imageries to detect and measure the aerial extent of change of the study area. The composite data layers of study year have been overlaid to generate a multi-temporal composite data layer. The composite data layer contains identification of each thematic data layer which was used for addressing it in order to generate area statistics as well as for assigning unique colour for a particular feature in the map. The attribute table of this composite data layer was rebuilt to generate multitemporal change-class with appropriate identification of each change class. 


\section{Results and Discussions \\ Object-based approach for image classification}

An object-based approach was used to classify land cover from moderate resolution satellite images of the study area of pre- and post-cyclone Aila time sequences. A total of five land cover classes were used: (i) barren land; (ii) crop; (iii) water bodies; (iv) vegetation; (v) others. An object-based approach to incorporate multiple spatial scales in the analysis through multi-scale segmentation process was essential to classify the land covers more accurately (Table 3 ). The spatial pattern of landuse/cover of six different upazila in the study area for before and after cyclone Aila is shown in Figure 3-8.

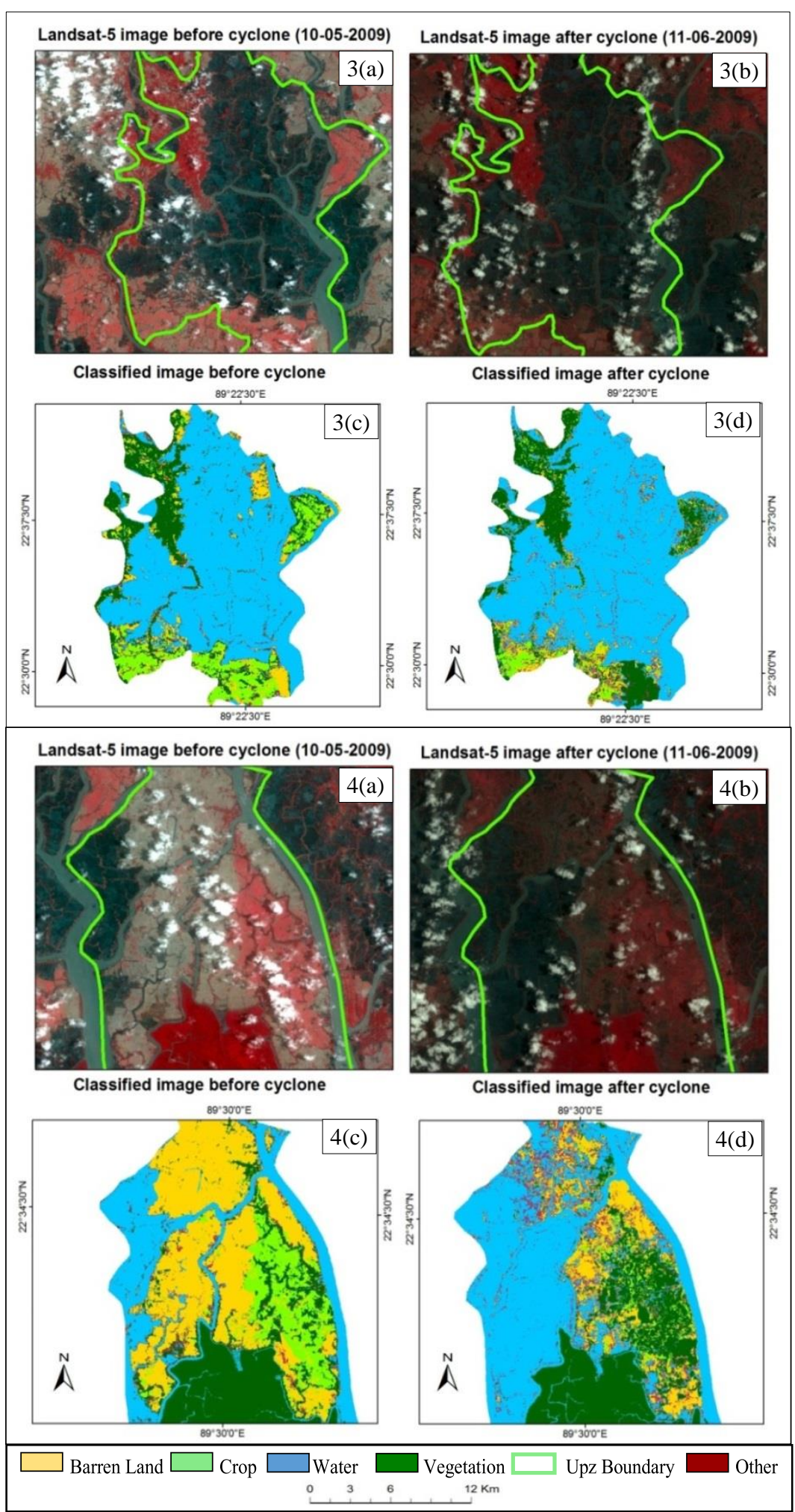

Fig. 3 and 4. Landuse/ Cover maps for pre- and post-cyclone condition corresponding to part of (3) Paikgachha upazila and (4) Dacope upazila as obtained through processing and analysis of Landsat TM images following methodologies as mentioned under the present work. 


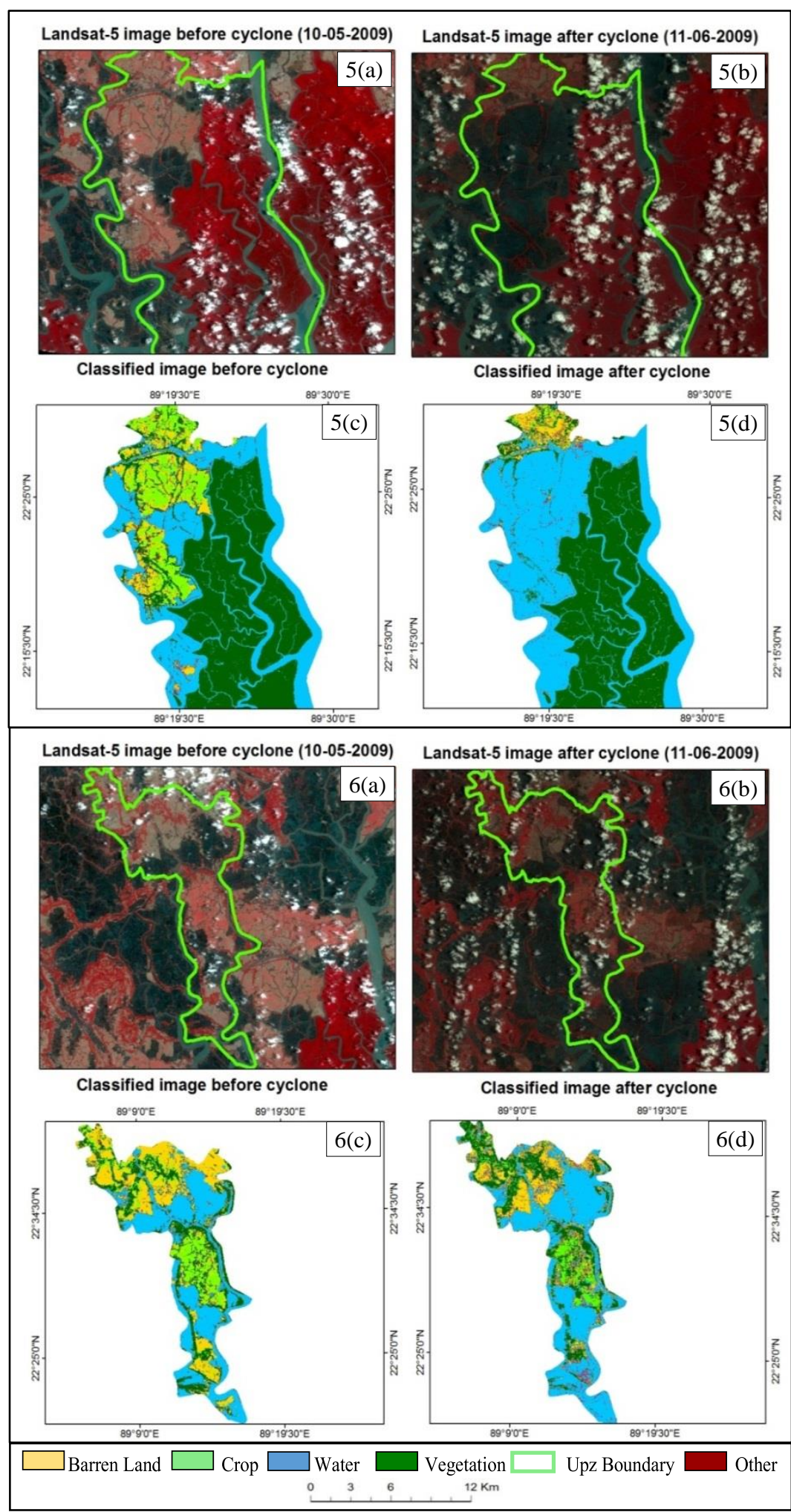

Fig. 5 and 6. Landuse/ Cover maps for pre- and post-cyclone condition corresponding to part of (5) Koyra upazila and (6) Assasuni upazila as obtained through processing and analysis of Landsat TM images following methodologies as mentioned under the present work.

In each of the figures (from figure 3 to figure 8), (a) represents the colour composite image of Landsat TM of pre-Aila-2009, (b) denotes the same as that of (a) except for the post-Aila-2009, (c) and (d) represents Landuse/ Cover maps for pre- and post-cyclone condition as obtained through processing and analysis of Landsat TM images following methodologies as mentioned under the present work.
The spectral colour composite image is produced as a combination of bands 3, 4 and 5 in the RGB sequences for the pre- and post-cyclone period. In the colour composite images, the whitish clusters represent scattered cloud cover over the area having relative high intensity values in all the three displayed spectral bands. 


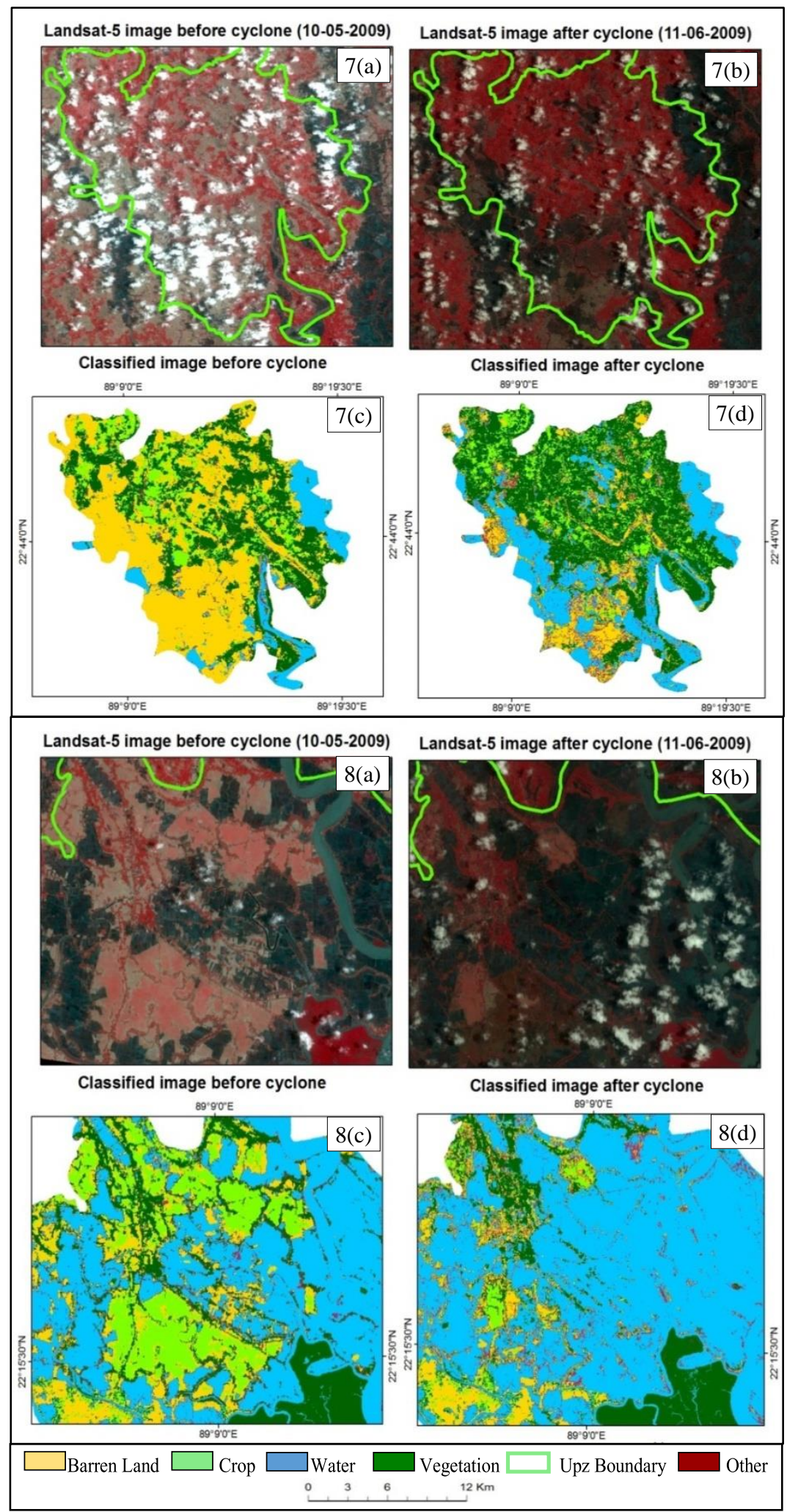

Fig. 7 and 8. Landuse/ Cover maps for pre- and post-cyclone condition corresponding to part of (7) Tala upazila and (8) Shamnagar upazila as obtained through processing and analysis of Landsat TM images following methodologies as mentioned under the present work.

Landuse/Cover statistics of six upazilas under the study area before and after the cyclone Aila-2009 have been given in tables 4 and 5 . From figure 8 , it is revealed that in the Shamnagar upazila, crop area has been decreased from 6,234 hectares to about 2,021 hectares while vegetation area has been decreased from 1,10,707 hectares to 107894 hectares after the cyclone Aila-2009 (Table 4 and 5). In contrary, water area has been increased from 61,695 hectares to 62,139 hectares. In the Assasuni upazila, crop area has been decreased from 3494 hectares to 2,339 hectare and vegetation area has been decreased from 6,220 hectare to 6,056 hectares after the cyclone Aila-2009. But water area increased from 10,513 hectares to 13,367 hectares. 
Table 4: Landuse/Cover Statistics of six different upazilas in the study area before the cyclone Aila in 2009.

\begin{tabular}{|c|c|c|c|c|c|c|c|c|c|c|c|c|}
\hline \multirow{3}{*}{$\begin{array}{l}\text { Landuse } \\
\text { Category }\end{array}$} & \multicolumn{2}{|c|}{ Shamnagar } & \multicolumn{2}{|c|}{ Assasuni } & \multicolumn{2}{|c|}{ Tala } & \multicolumn{2}{|c|}{ Paickgacha } & \multicolumn{2}{|c|}{ Koyra } & \multicolumn{2}{|c|}{ Dacope } \\
\hline & \multicolumn{2}{|c|}{ Area } & \multicolumn{2}{|c|}{ Area } & \multicolumn{2}{|c|}{ Area } & \multicolumn{2}{|c|}{ Area } & \multicolumn{2}{|c|}{ Area } & \multicolumn{2}{|c|}{ Area } \\
\hline & hectare & $\%$ & hectare & $\%$ & hectare & $\%$ & hectare & $\%$ & hectare & $\%$ & hectare & $\%$ \\
\hline Barren land & 31170.08 & 5.21 & 7294.77 & 1.22 & 15408.10 & 2.58 & 2655.54 & 0.44 & 6091.20 & 1.02 & 12623.10 & 2.11 \\
\hline Water & 61694.50 & 10.32 & 10512.81 & 1.76 & 3298.14 & 0.55 & 24932.89 & 4.17 & 83430.50 & 13.95 & 19948.64 & 3.34 \\
\hline Crop & 6233.94 & 1.04 & 3493.71 & 0.58 & 3978.09 & 0.67 & 3644.64 & 0.61 & 5683.68 & 0.95 & 3762.81 & 0.63 \\
\hline Vegetation & 110707.00 & 18.52 & 6220.53 & 1.04 & 10468.40 & 1.75 & 6305.58 & 1.05 & 98646.10 & 16.50 & 50333.10 & 8.42 \\
\hline Other & 3094.74 & 0.52 & 1289.34 & 0.22 & 685.08 & 0.11 & 1287.18 & 0.22 & 2009.70 & 0.34 & 1024.29 & 0.17 \\
\hline & & & & & & & & ou & Result $f$ & $L a$ & image & alysis \\
\hline
\end{tabular}

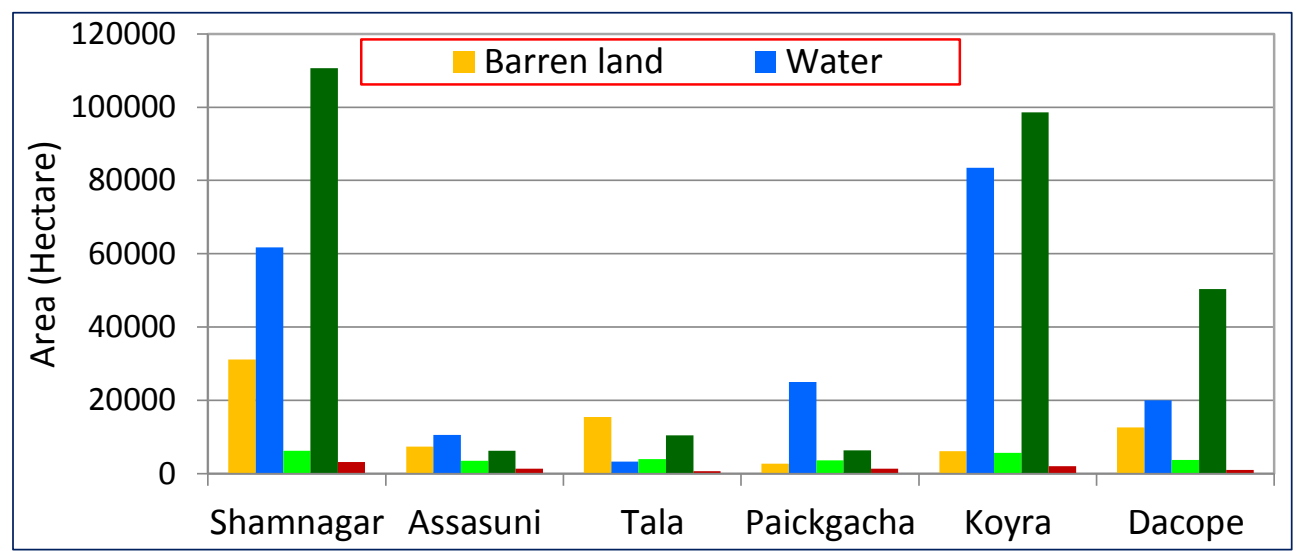

Fig. 9. Landuse/Cover statistics in six different upazilas of the study area before the cyclone Aila2009. Results have been obtained through processing and analysis of Landsat TM images following methodologies as mentioned earlier under the present work.

Table 5: Landuse/Cover Statistics of six different upazilas in the study area after the cyclone Aila-2009.

\begin{tabular}{|c|c|c|c|c|c|c|c|c|c|c|c|c|}
\hline \multirow{3}{*}{$\begin{array}{l}\text { Landuse } \\
\text { Category }\end{array}$} & \multicolumn{2}{|c|}{ Shamnagar } & \multicolumn{2}{|c|}{ Assasuni } & \multicolumn{2}{|l|}{ Tala } & \multicolumn{2}{|c|}{ Paickgacha } & \multicolumn{2}{|c|}{ Koyra } & \multicolumn{2}{|c|}{ Dacope } \\
\hline & \multicolumn{2}{|l|}{ Area } & \multicolumn{2}{|l|}{ Area } & \multicolumn{2}{|l|}{ Area } & \multicolumn{2}{|l|}{ Area } & \multicolumn{2}{|c|}{ Area } & \multicolumn{2}{|c|}{ Area } \\
\hline & hectare & $\%$ & hectare & $\%$ & hectare & $\%$ & hectare & $\%$ & hectare & $\%$ & hectare & $\%$ \\
\hline Barren land & 36433.39 & 6.09 & 3944.79 & 0.66 & 3706.47 & 0.62 & 1713.60 & 0.29 & 3341.79 & 0.56 & 4100.49 & 0.69 \\
\hline Water & 62139.20 & 10.39 & 13367.47 & 2.23 & 8455.32 & 1.41 & 27335.18 & 4.57 & 93472.20 & 15.63 & 28642.60 & 4.79 \\
\hline Crop & 2021.22 & 0.34 & 2338.65 & 0.39 & 4386.87 & 0.73 & 1459.62 & 0.24 & 849.42 & 0.14 & 851.85 & 0.14 \\
\hline Vegetation & 107894.00 & 18.04 & 6056.37 & 1.01 & 14600.60 & 2.44 & 5987.07 & 1.00 & 96194.20 & 16.08 & 50919.70 & 8.51 \\
\hline Other & 4375.35 & 0.73 & 3096.90 & 0.52 & 2706.12 & 0.45 & 2337.48 & 0.39 & 2191.50 & 0.37 & 3212.55 & 0.54 \\
\hline
\end{tabular}

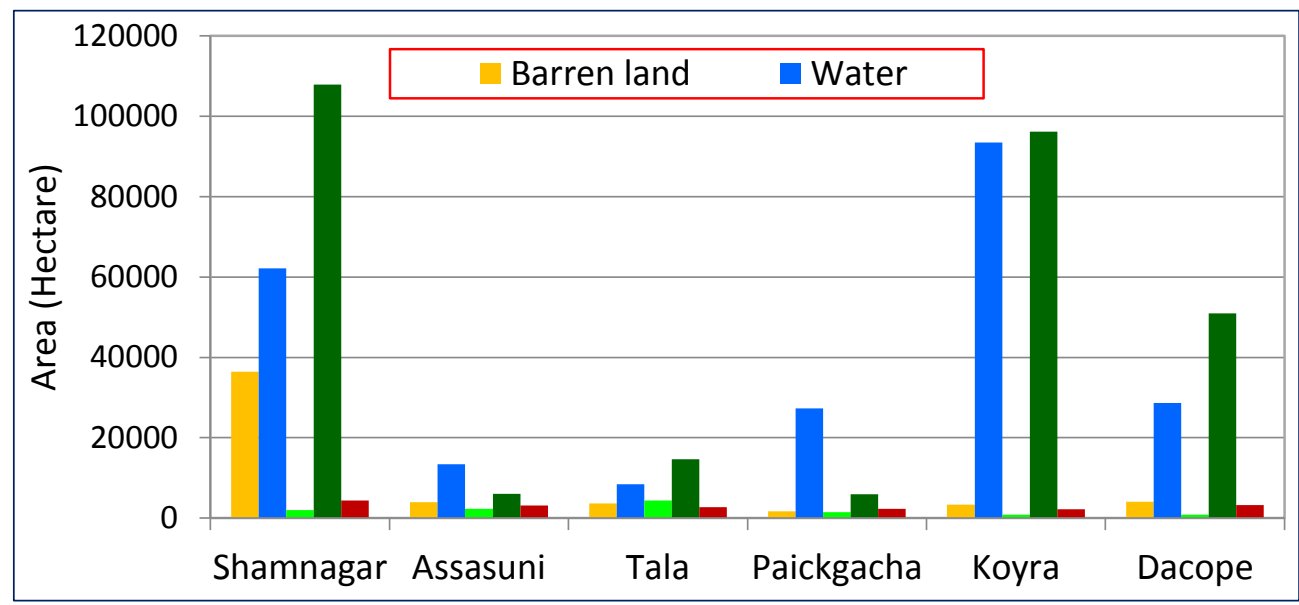

Fig. 10. Same as in figure 9, except results represent the post cyclone Aila -2009 condition. 
From the analysis of satellite images, similar scenario was observed for rest of the upazilas. Crop and vegetation areas were decreased in each upazilas whereas water area was increased significantly. A decreasing trend in case of barren land area has been observed in each upazila except Shamnagar after cyclone-2009 hit the area. Variations of land cover pattern for the pre- and post-cyclone Aila-2009 time period in the study area have been presented in the bar diagrams in figures 9 and 10).

\section{Change Detection}

Post-classification comparison change detection algorithm was used to investigate the land cover changes between pre- and post-cyclone Aila classified images for damage assessment. Post classification has been successfully used by a number of researchers for tropical cyclone impact assessment (Dewan and Yamaguchi, 2009). Cross tabulation analysis was performed to analyze the spatial distribution of land cover changes.
The comparison of post-classification results provided cyclone land cover classes to assess the damages. It was assumed that within 30 days interval between two images, the changes occurred in the study area land covers just only for tropical cyclone Aila. The descriptive statistical analysis is performed from the change matrix to quantify the degree and extent of damages of a particular land cover type due to cyclone in the study area (Table 6).

The results indicate that mainly barren land, cropland and vegetation of the study area were damaged moderately to highly by the impacts of tropical cyclone Aila. This was indicated by class transitions from barren land, cropland and vegetation to water bodies. Major damage was identified for cropland, vegetation and barren land. Around 8,163 hectares cropland area was flooded by cyclone induced surge water and totally damaged which is $1.37 \%$ of total area (Table 6).

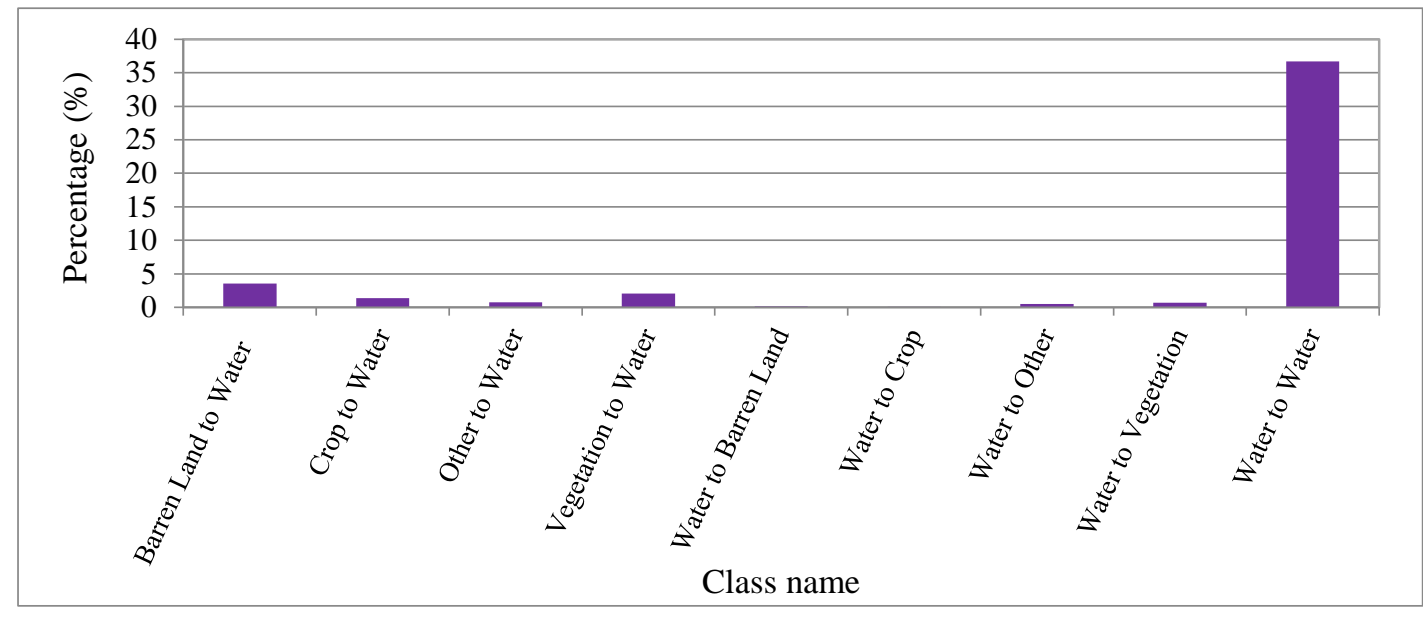

Fig. 11. The percentage of changes of land covers caused by tropical cyclone Aila in the study area.

Table 6: Change Matrix of water area in the study area after cyclone Aila in 2009.

\begin{tabular}{|c|c|c|}
\hline Class name & Area (hectare) & Area $(\%)$ \\
\hline Barren Land to Water & 21,047 & 3.53 \\
\hline Crop to Water & 8,163 & 1.37 \\
\hline Other to Water & 4,427 & 0.74 \\
\hline Vegetation to Water & 12,278 & 2.06 \\
\hline Water to Barren Land & 848 & 0.14 \\
\hline Water to Crop & 74 & 0.01 \\
\hline Water to Other & 3,013 & 0.50 \\
\hline Water to Vegetation & 4,140 & 0.69 \\
\hline Water to Water & $2,18,991$ & 36.69 \\
\hline
\end{tabular}

Source: Result from Landsat image analysis

In the present study, a direct change detection approach has been adapted using two sets of images acquired before and after the cyclone Aila-2009 event to produce a principal component composite images and a set of image difference bands. Techniques in the comparison include supervised classification, unsupervised classification, and object-oriented classification approach with a nearest neighbor classifier. GPS-based ground truthing operation has been carried out for selected features at specific geographical locations. 
Calculation of Kappa coefficients put a basis for accuracy assessment from error matrices which cross tabulate correctly identified cells on the TM image and commission and omission errors in the result. Overall, the Object-oriented Approach exhibits the highest degree of accuracy in tornado damage detection. PCA and Image Differencing methods show comparable outcomes. While selected PCs can improve detection accuracy 5 to $10 \%$, the Object-oriented Approach performs significantly better with $15-20 \%$ higher accuracy than the other two techniques.

The percentage of changes of land covers caused by tropical cyclone Aila in the study area is represented by the bar diagram (Figure 11). The spatial pattern of landuse/cover change in the study area due to cyclone surge water flooding of various land covers between preand post- cyclone Aila images is shown in Figure 12. Result from change analysis (Figure 12) reveals that, after cyclone Aila $3.53 \%$ of barren land area changed into water area; $1.37 \%$ cropland area flooded and $2.06 \%$ of vegetation land changed into water area (Table 6). Water bodies increased significantly in extent due to cyclone surge water flooding of various land covers. $36.69 \%$ changed occur from water body to water body.

The spatial distribution pattern of net change of water area due to cyclone surge water flooding of various land covers between pre- and post- cyclone Aila images is shown in Figure 13. Table 7 explained the total change scenario between pre- and post- cyclone Aila time with the transformation statistics of flooded area. The net change column shows the direction or behavior of change. Negative values indicate decrease and positive values indicates increase in land cover feature. From Table 7 it is clear that about 37,839 hectares area was flooded after cyclone hit. In majority of the cases, disaster management initiatives mostly require detailed spatial information on the extent and forms of cyclone induced damage and the specific land cover and land use types affected. Useful information on disaster events to facilitate any sort of management initiatives may be provided by applying remote sensing technology. Technique of change detection applying classified images is a widely used technique to support this process in a remote sensing environment (Wang and XU, 2010).

\section{Remote Sensing-GIS Analysis of Geo-Environmental Consequences}

The processes of evaluation or assessment of the consequences of a given disaster event requires a certain number of spatial input parameters or information; those are pertinent to the major biophysical processes that eventually condition the geographical area under observation. Individual process parameters are to be retrieved applying standard methodology and algorithm preferably using space-based remote sensing and GIS technologies.

Figure 14 represents part of Koyra union under Koyra Upazila, Khulna District as observed in Google image of 2009 corresponding to pre-cyclone Aila. While image of 2011 corresponding to post-cyclone Aila time sequences. Comparison of Figures $14 \mathrm{a}$ and $14 \mathrm{~b}$ provide certain differences in surface feature configuration over the area.

\section{Erosion and Formation of New Canal}

From post-Aila image of 2011 (Figure 14B) a newly created canal named Pabna canal is observed. The length of the canal is about $2 \mathrm{~km}$ and width varies from place to place along canal length. Canal width at six different locations with their geographical position is listed in Table 8.

It is also to be mentioned that deposition of sand has been observed along both bank of the Pabna canal in the post Aila image of 2011 (Figure 14b). After the landfall of the cyclone Aila, inundation of large area is observed from the upper part of the post Aila image of 2009. Eventually this inundated area forms the newly developed Pabna canal. Erosion occurs along the Sakbaria River and increase River width of about $17 \mathrm{~km}$ along its right bank has been noticed.

\section{Damages of Embankments}

Analysis of time series satellite data indicate that devastating Cyclone Aila bleached nearby embankments, roads and settlements, damaged ghers and agriculture fields, increased the widths and depth of channels, developed new channels. Figure 15 represents a small part under the study area as appeared in the highresolution Google Earth image covering the river along with the embankment (left). On the right, zoomed images represents a small part of the river where embankment has been damaged. High resolution optical data provides information on the damages of embankment in the image. Damages of the embankment are clearly visible in the optical image. Such a situation offered the water in the network to spread towards the surrounding areas through the damaged embankment positions. Ground data collection at selected location and discussion with the local people therein provided important information on certain aspects of the cyclone Aila-2009..

Table 7: Change Statistics of Water area after cyclone Aila in the study area.

$\begin{array}{ccccc}\text { Duration } & \begin{array}{c}\text { Water area increase } \\ \text { (hectare) }\end{array} & \begin{array}{c}\text { Water area decrease } \\ \text { (hectare) }\end{array} & \begin{array}{c}\text { Net change (increase/decrease) of } \\ \text { Water area } \\ \text { (hectare) }\end{array} & \begin{array}{c}\text { Common Water area } \\ \text { (hectare) }\end{array} \\ \begin{array}{c}10-05-2009 \\ \text { to }\end{array} & 45915 & 8075 & +37839 & 218991 \\ 11-06-2009 & & & \end{array}$




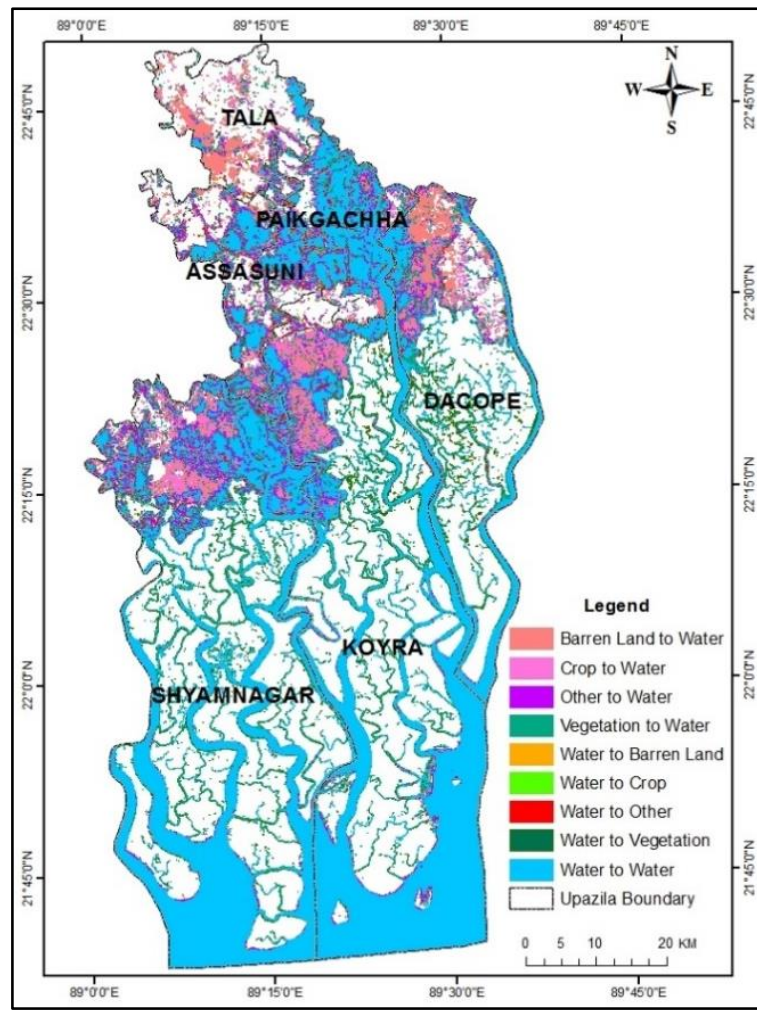

Fig. 12. Transformation of class categories corresponding to six different upazilas under present study after cyclone Aila-2009 as obtained through processing and analysis of Landsat TM images following methodologies as mentioned under the present work.

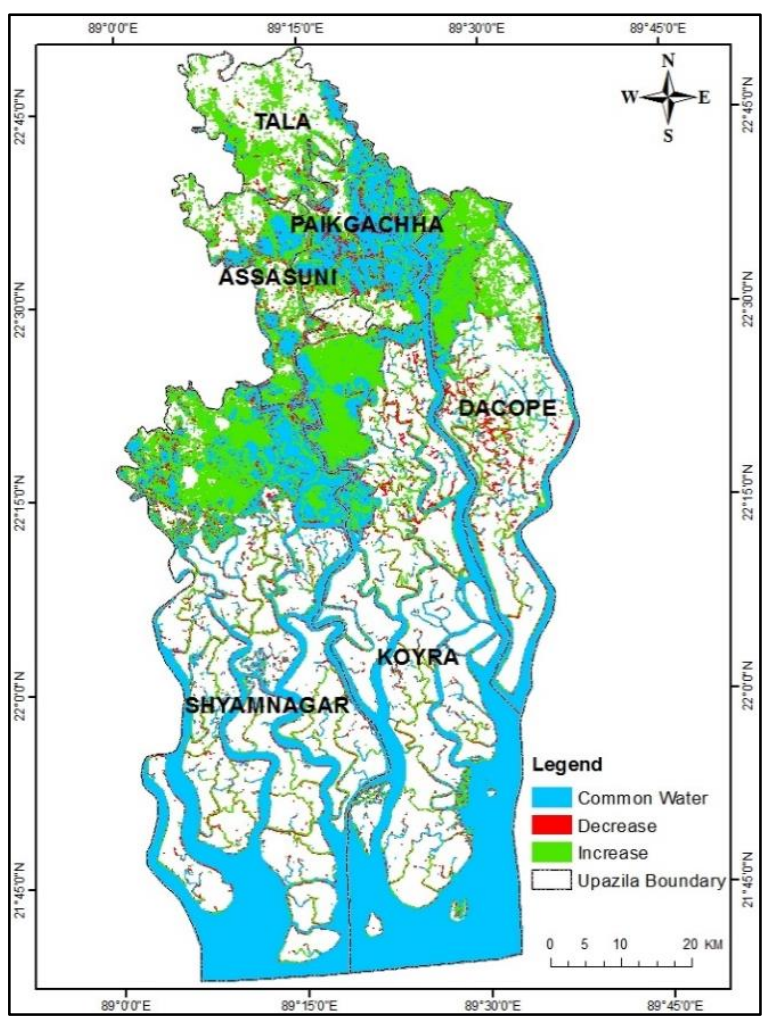

Fig. 13. Water area increase-decrease map for the six upazilas under the present study after cyclone Aila-2009 as obtained through processing and analysis of Landsat TM images following methodologies as mentioned under the present work.

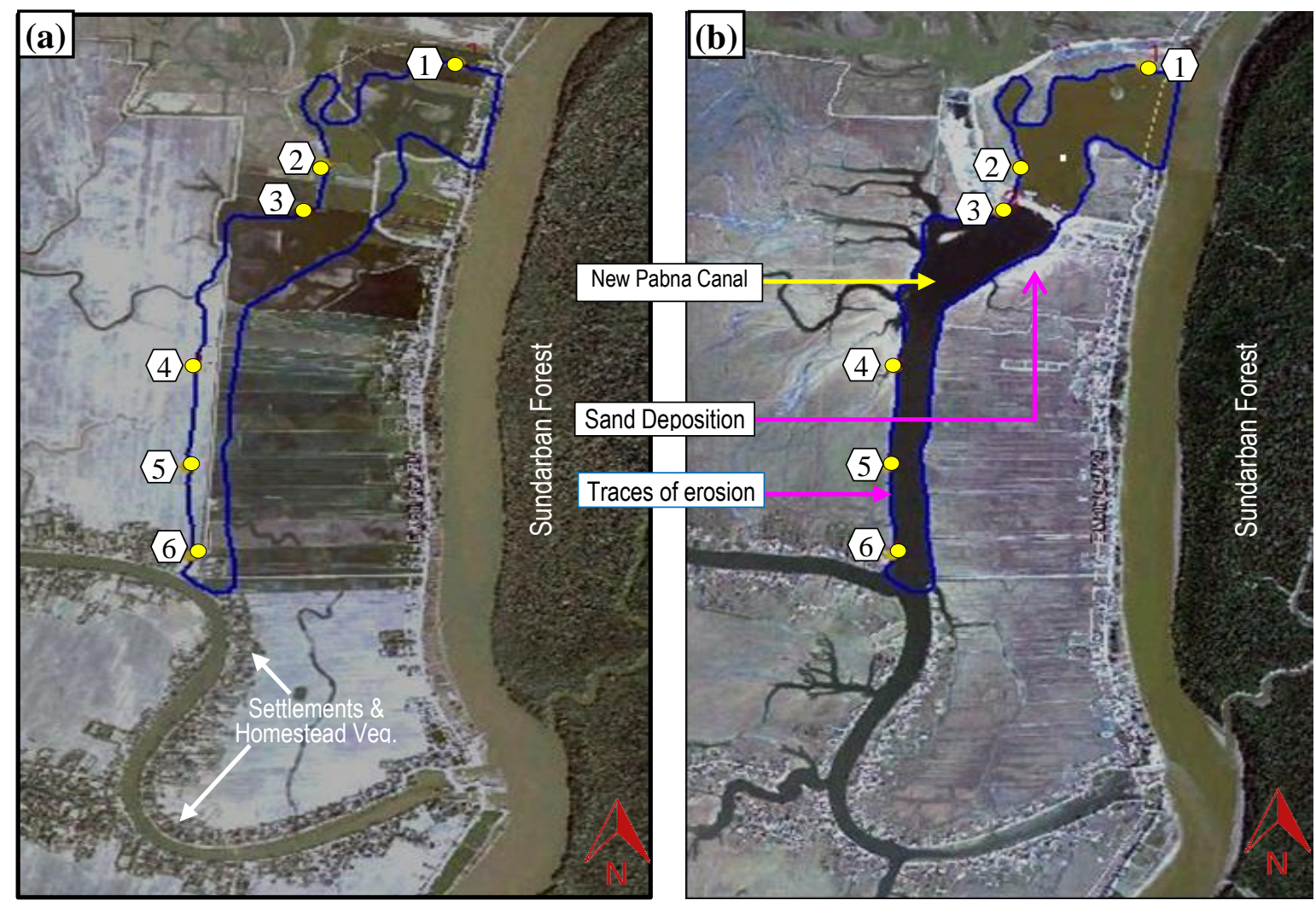

Figure 14: Extracted Google image shows the (a) pre-Aila 2009 condition and (b) post-Aila 2011 condition respectively. Newly created Pabna canal (b) and erosion along the Sakbaria River. Length of the New Pabna Canal is about $2 \mathrm{~km}$. The widths of the Canal at different positions are given in table 8 . 


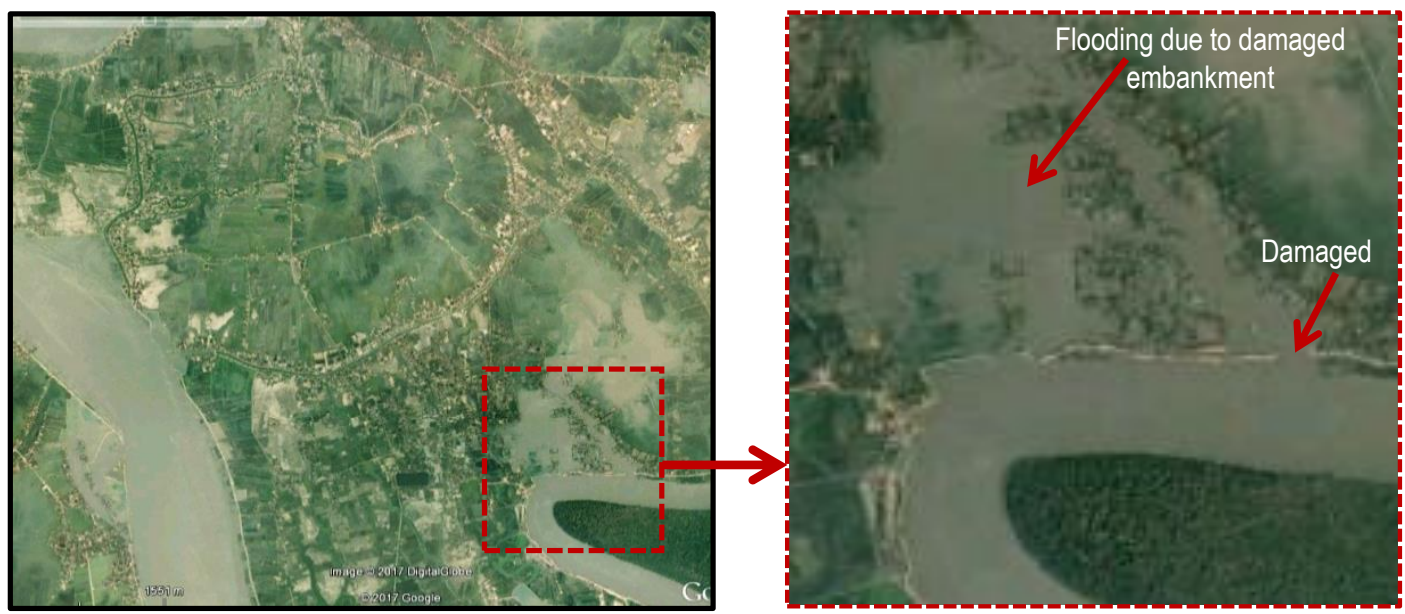

Figure 15: Worldview (Google) colour composite image of March 1, 2010 (Post Aila-2009) shows a small part of the present study: Damaged embankment allowing river water to spread up over the nearby land areas.

Cyclone Aila, which swept across areas of southern Bangladesh and eastern India on 25 May 2009, caused widespread damages and affected a significant number of populations living in the area under the present study. In southern Bangladesh, the cyclone caused a tidal surge which broke through poorly maintained coastal embankments. In south western districts, especially in Shatkhira and Khulna, people living in the coastal villages were forced to flee to raise embankments as houses and crops became submerged under water. The horrifying fact is that nearly $2,000 \mathrm{~km}$ of the coastal embankment) was damaged, causing extensive flooding.

Figure 15 shows Worldview (Google) colour composite image of March 1, 2010 (Post Aila-2009) showing a small part of the present study: Damage embankment allowing river water to spread up over the nearby land areas. Cyclone Aila exerted pressure on the dam, causing damage and removal at certain position. Water pressure drives water to overflow over the nearby areas.

Hitting during high tide, the cyclone brought with it tidal surges of up to 6.5 meter, affecting 11 coastal districts. This surge of water damaged and washed away over $1,742 \mathrm{kms}$ of embankments, removing the only protection available to many people along the coast. The storm lingered over the coast of Bangladesh for a comparatively longer time than Cyclone SIDR (2007), which further increased its devastations. In many areas the damage to the network of embankments has resulted in a prolonged continuation of what affected communities faced in the immediate aftermath of the cyclone - flooding. Breeches in the embankments, which become severe during daily high tides, and particularly during periods of full moon, have prevented the high levels of self- recovery normally seen in Bangladesh following disaster events. The damage to the coastal embankment network was severe and has directly contributed to the continuation of the post- cyclone scenario (widespread flooding and tidal inundation) currently faced by the worst affected communities.

\section{Flooding and Water Logging}

Figure 16 shows Landsat TM spectral colour composite images RGB $(5,4,3)$ of dated (a) May 10, 2009 representing Pre-Aila and (b) June 11, 2009 representing Post-Aila time sequences. These figures principally demonstrate the cropping activities and inundated areas respectively in part of Koyra and Dacope upazilas under Khulna district caused by the cyclone Aila 2009. These figures represent the changes of surface features within the image area. Comparison of the images of two dates shows significant increase in water covered areas between pre- and post-Aila time sequences. Extended flooding in terms of duration and spatial coverage have been noticed during post-Aila period as compared to other time sequence. Cyclone Aila accompanied by storm surges, flooded the villages and crop fields with saline water from the Bay of Bengal. The incoming seawater caused two-fold effects in the area e.g., (i) water logging in certain areas at different locations depending on the surface characteristics and (ii) salinity due to incoming water significantly affected the agroenvironmental setup in the area. Ultimately, the prolonged water logging over the area with relatively high salinity had affected most of the vegetation were seriously affected, died and disappeared. Figures 16a and $16 \mathrm{~b}$ represent a small part of the affected area as pre- and post-Aila condition as derived through processing and analysis of Landsat TM satellite sensor data. Salinity in the coastal area had become severe, forcing saline water to spread over the cultivated lands. As an aftermath huge area has been exposed for a long time to the regular tidal processes by sea water with high salinity. The seawater flooded villages and fields. Thousands of kilometers of road were seriously damaged or totally destroyed and hundreds of kilometers of flood protection embankments were washed away. Salinity is one of the major problems in the coastal region of Bangladesh that contributes to $20 \%$ of the total land area. About $53 \%$ of the coastal region is affected by different degrees of salinity. Salinity intrusion in this area is mainly derived through climate change as well as anthropogenic factors that make this region more vulnerable. 
Table 8: Width of newly created Pabna Canal at different locations.

$\begin{array}{cccc}\text { Point ID } & \text { Longitude } & \text { Latitude } & \text { Channel width (m) } \\ 1 & 89^{\circ} 1951.47 \mathrm{E} & 22^{\circ} 2207.45 \mathrm{~N} & 298 \\ 2 & 89^{\circ} 1939.33 \mathrm{E} & 22^{\circ} 2156.00 \mathrm{~N} & 192 \\ 3 & 89^{\circ} 1937.52 \mathrm{E} & 22^{\circ} 2151.00 \mathrm{~N} & 199 \\ 4 & 89^{\circ} 1927.43 \mathrm{E} & 22^{\circ} 2133.25 \mathrm{~N} & 99 \\ 5 & 89^{\circ} 1926.83 \mathrm{E} & 22^{\circ} 2122.03 \mathrm{~N} & 88 \\ 6 & 89^{\circ} 1927.16 \mathrm{E} & 22^{\circ} 2112.05 \mathrm{~N} & 104\end{array}$

Source: Result from Google image analysis
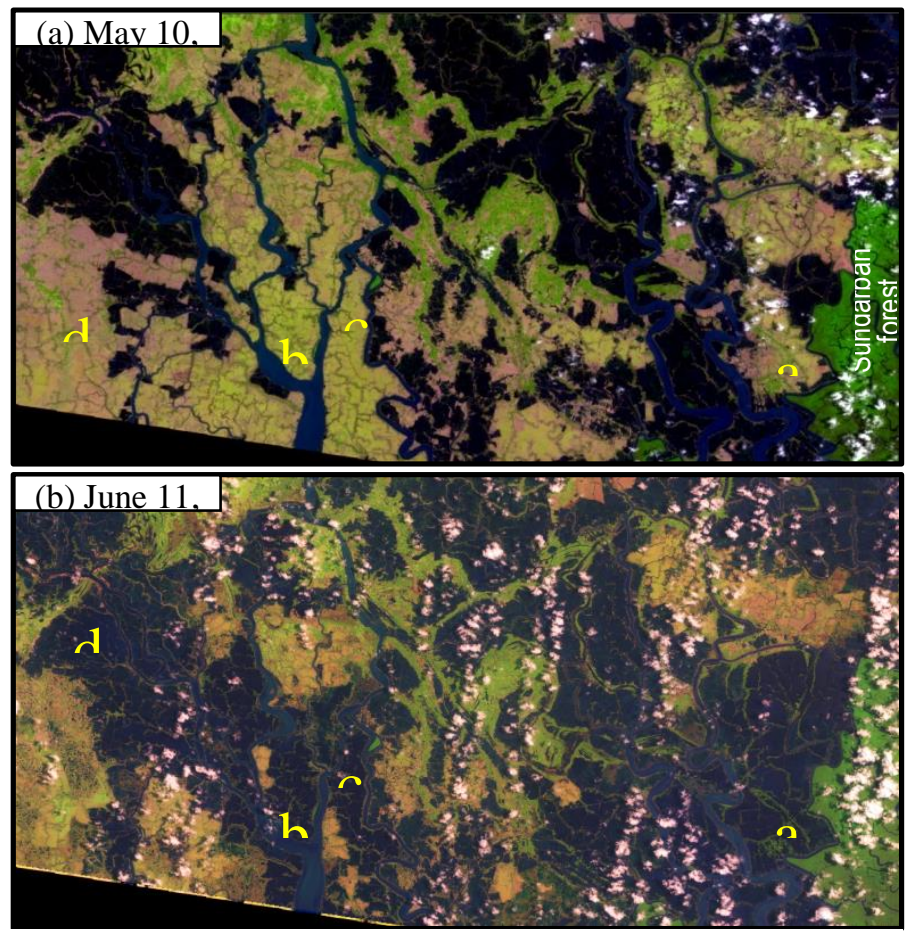

Figure 16: Landsat TM spectral colour composite images RGB (5, 4, 3) of dated (a) May 10, 2009 (Pre Aila) and (b) June 11, 2009 (Post Aila) representing the changes of surface features within the image area. Figure mainly shows the cropping activities and inundation respectively in part of Koyra and Dacope upazila under Khulna district due to cyclone Aila 2009.

As Bangladesh belongs to one of the seaside countries, the adverse impact of saltwater intrusion is significant here. Salinity mainly affects land and water in the coastal areas (Mahmuduzzaman et al. 2014). With the consequence of climate change, it gradually extends towards inland water and soil. This scenario of gradual salinity intrusion in the coastal area of Bangladesh is very threatening to the primary production system, coastal biodiversity and human health.

\section{Damages of Vegetation}

Figures $17 \mathrm{a}$ and $17 \mathrm{~b}$ exhibit extracted images of Google spectral colour composite images of (a) November 27, 2008 and (b) March 1, 2010 representing pre-Aila and post-Aila situation respectively in part of the Koyra upazila under Khulna district. The presence of water covering the settlement areas is very much visible in image of figure (b) as compared to that with image (a). The presence of trees and vegetation in figure 17(a) as textured elements is readily visible over the settlement areas. Whereas, such texture is almost absent in figure 17(b) indicating probable destruction of trees and vegetation.

Figure 17a indicates the presence of vegetation and trees that appeared as textured elements distributed around the settlement areas. While most of the vegetation areas have been disappeared on the post Aila images of 2010 (Figure 17b). Moreover, a significant area over the settlement also disappeared on the post Aila image. Moreover, presence of water over many areas is readily visible in the high spatial resolution satellite images.

Cyclone Aila-2009 accompanied by high intensity winds, storm-water surges, tidal inundation, saline water invasion and flash floods caused significant damages to the people dependent on the fragile landscape for their life and livelihood generation activities and biodiversity. Resulting effect at the surface level due to land cover changes significantly affected the biophysical and 
radiative properties of the land-surface over the area. Biophysical characterization of spectral radiative measurements provides enhanced capability and precision for radiative data interpretation. The condition and cover changes over the area in the nost-cvclone time

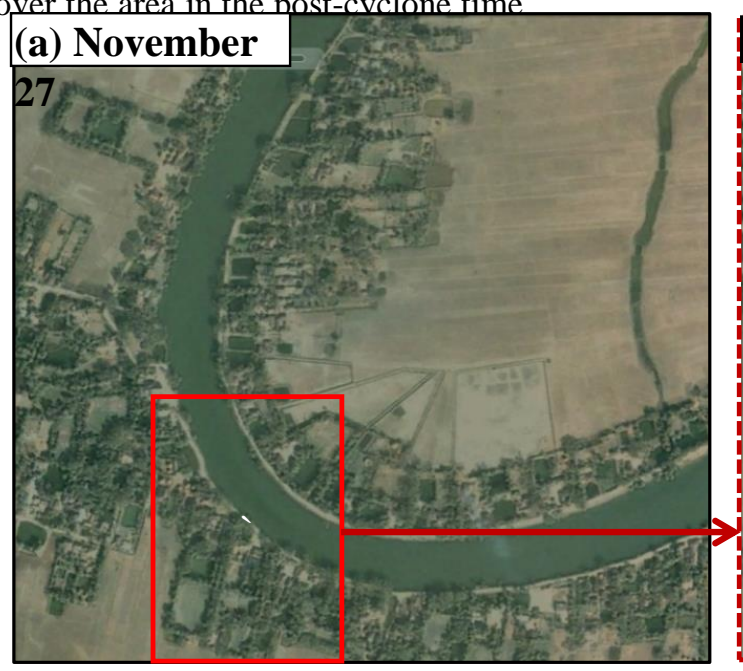

period caused noticeable modification of radiative transfer budgeting particularly, through the surface albedo, and surface temperature in the area under exposure of cyclone Aila-2009.

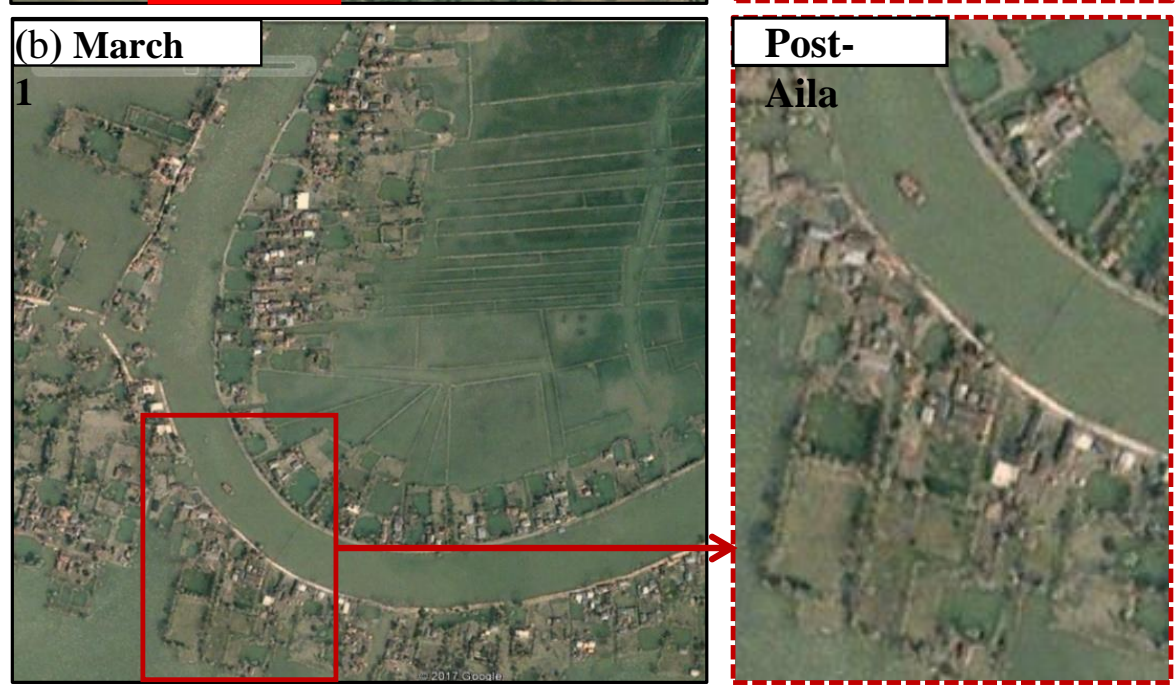

Fig. 17. Extracted Google TM spectral colour composite images of (a) November 27, 2008 and (b) March 1, 2010 representing pre-Aila and post-Aila situation respectively in part of the Koyra upazila under Khulna district.

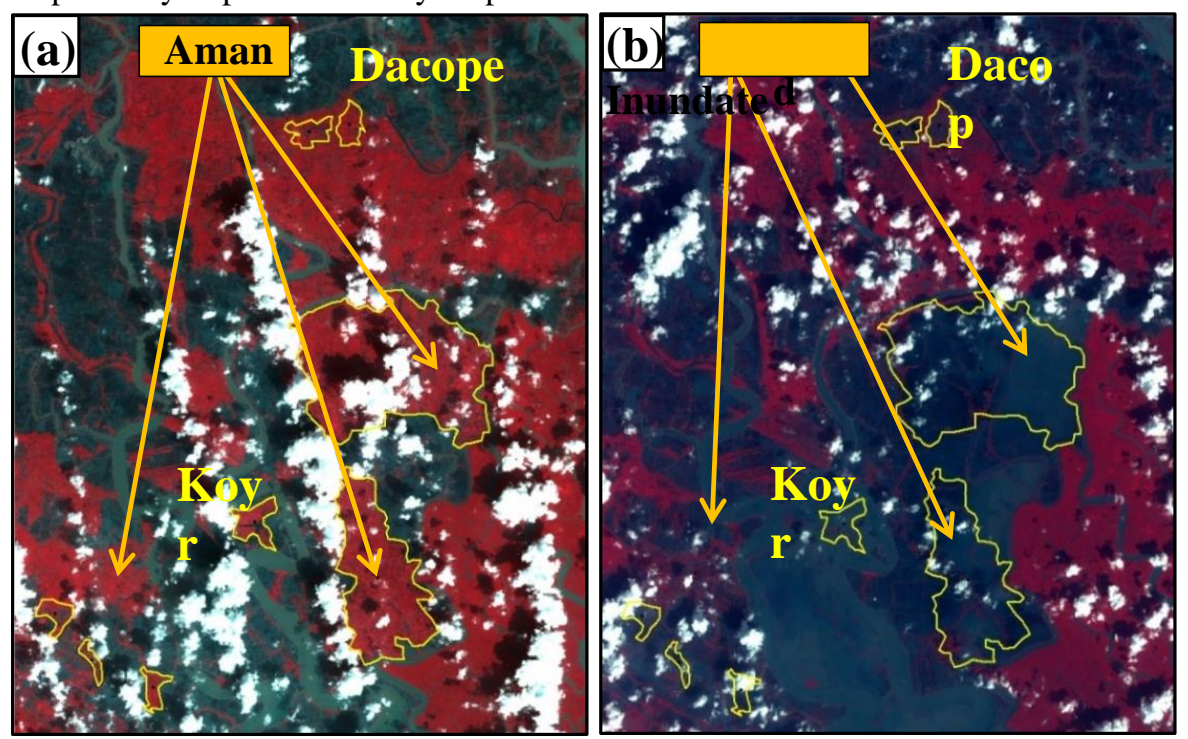

Fig. 18. Landsat TM spectral colour composite images RGB $(4,3,2)$ of dated (a) October 30, 2008 (Pre Aila) and (b) 17 October 2009 (Post Aila) representing changes of cropping activities and inundation respectively in the Koyra and Dacope upazilas. 


\section{Damages of Cropland}

Figure 18 represents Landsat TM spectral colour composite images RGB $(4,3,2)$ of dated (a) October 30, 2008 of Pre-Aila and (b) 17 October 2009 of Post-Aila time sequences. Figures represent changes of cropping activities and inundation respectively in the Koyra and Dacope upazila under Khulna district due to cyclone Aila. The figures demonstrate that relatively large areas are presently under water in the post-Aila time period which was previously under Aman crop areas in the preAila image. This area usually shows excess salt content and thus not very suitable for cultivation. Such a situation largely limits crop cultivation in the area and as such restricting any sort of cultivation according to crop calendar at the present time. The whitish cluster followed by an adjacent dark shadow generally represents cloud clusters over the Landsat images.

\section{Image-Based Spectral Characterization of Surface Features}

Cyclone Aila introduced dynamic changes in the geoenvironmental configuration and composition of surface features over the study area with different cascading effects of parameters and processes. Remote sensing spectral measurements are principally controlled by the interaction of radiative signal with different earth's surface materials. Findings of this study are in agreement with the IPCC prediction "Impacts of Climate Change on aquatic ecosystems having adverse consequences for the world's 36 million fisher folk, through multiple pathways including changes in fish stock distribution and abundance, and destruction of fishing Gher and infrastructure in storms and severe weather events" as stated in the IPCC report (IPCC, 2007).
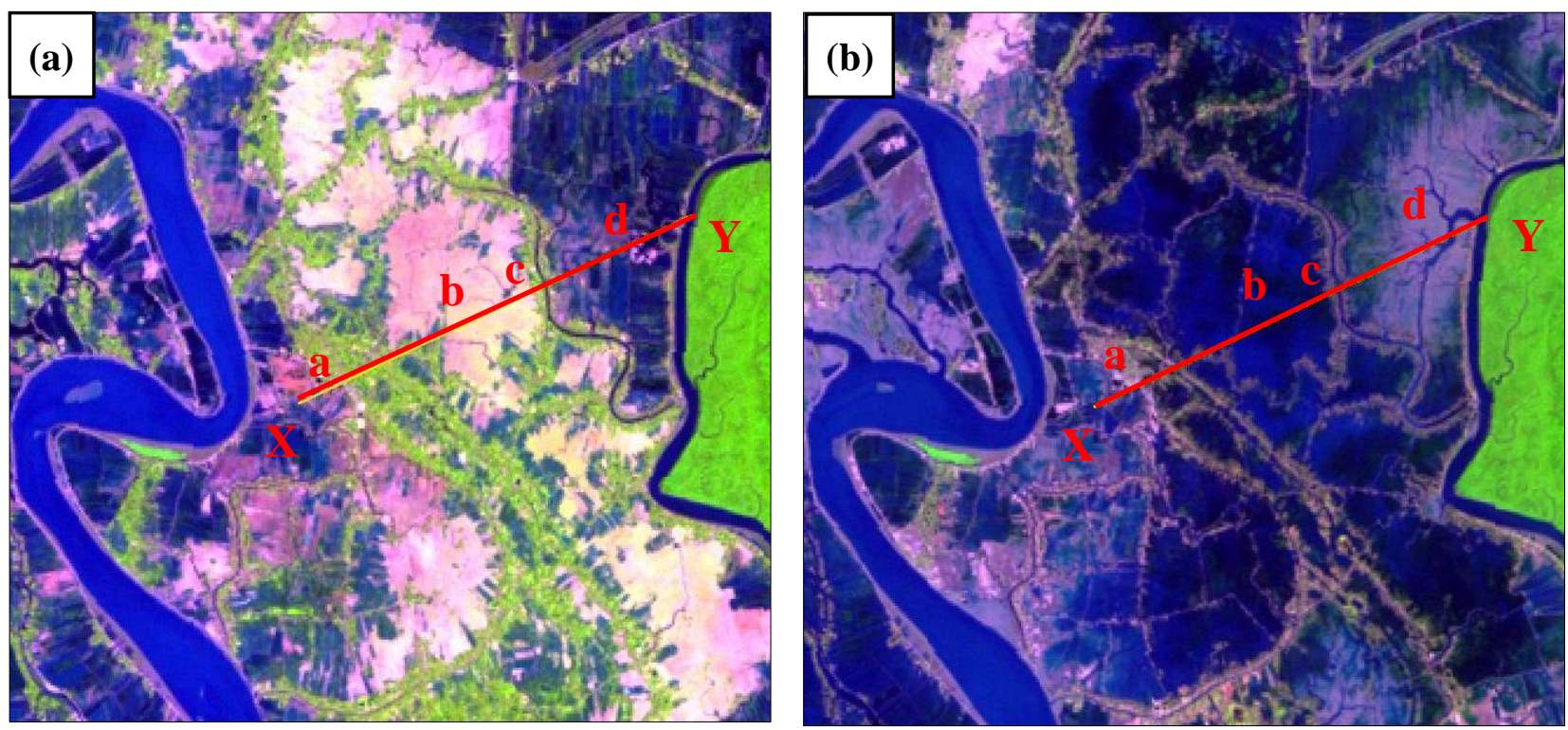

Fig. 19. Landsat TM spectral colour composite images R, G, B in three spectral bands (5, 4, and 3) of dated (a) of February 3, 2009 representing pre-Aila and of (b) February 6, 2010 representing post-Aila time sequences respectively in the Koyra upazila under Khulna district.

Figure 19 shows the Landsat TM spectral colour composite images of February 3, 2009 and February 6, 2010 representing (a) pre-Aila and (b) post-Aila situation respectively in the Koyra upazila under Khulna district. Landsat TM bands 3, 4 and 5 have been loaded in the B, $\mathrm{G}$ and $\mathrm{R}$ plains respectively of the display device. Spatial profiles have been drawn along a straight line (XY) over the two images. The readily noticeable bluish characteristics of the post-Aila-2009 image as compared to that of pre-Aila-2009-time sequence provide the evinces of storm surge driven water coverage over the area.

The graph in the figure 20 shows the variation of spectral reflectance values in bands 4 and 5 of Landsat TM along a linear profile on two different dates as mentioned. Along the profile a number of specific locations e.g., a, $\mathrm{b}, \mathrm{c}$ and $\mathrm{d}$ has been considered over both the images as shown in figure. Dynamic variation of reflectance values along the profiles on two dates have been interpreted in terms of surface category, its condition and transformation into another category. Profile lines as a function of distance exhibit significant variation of surface radiative intensity over the profiling direction.

Presence of water along the profile line, vegetation and soil radiative properties together determined the intensity of the signal in different spectral bands of Landsat Thematic Mapper (TM) sensor. The optical and architectural properties of vegetation and its density, moisture content of the soil particularly important in relatively low-density vegetation cover collectively determine the overall radiative characteristics of the vegetation canopy system. In such deterministic processes through vegetation phenology, dynamic soil moisture condition plays important role. The role of 
overspreading water has a dual role to play in this regard.

Water itself influences the overall canopy radiative characteristics. In addition, presence of salinity in the water affects the vegetation condition bringing a degradation of vegetation condition with respect to time. In the present work, atmospheric effects in the multidate satellite images have been removed through application of atmospheric correction procedure with consideration of atmospheric aerosol and molecular scattering. The presence of homestead vegetation as appeared in green colour in the image of February 2, 2009 (figure 19(a) is not visible in the post-cyclone image of February 6, 2010 as in figure 19 (b), though both the images correspond to almost same time of the year ( $1^{\text {st }}$ week of February). has possibility to increase in intensity (IPCC, 2007). The present study results are found to be in agreement with the IPCC statements.

Cyclone Aila hit 14 districts of south-west coastal region of Bangladesh on 25 May 2009 with wind speed of up to $90 \mathrm{~km}$ per hour. Cyclone Aila-2009 severely affected Satkhira and Khulna districts. Time series of satellite images, socio-economic census data, focus group discussions (FGD) outcomes, and other ancillary information have been analyzed. The cyclone had killed a significant number of people in the area, damaged or destroyed a large number of houses, damaged roads, embankments, many rural structures and shrimp farms over the area (USAID, 2015; Ahmed et al., 2016 and Bishawjit et al., 2017, Roy et al., 2009, Kumar et al.,

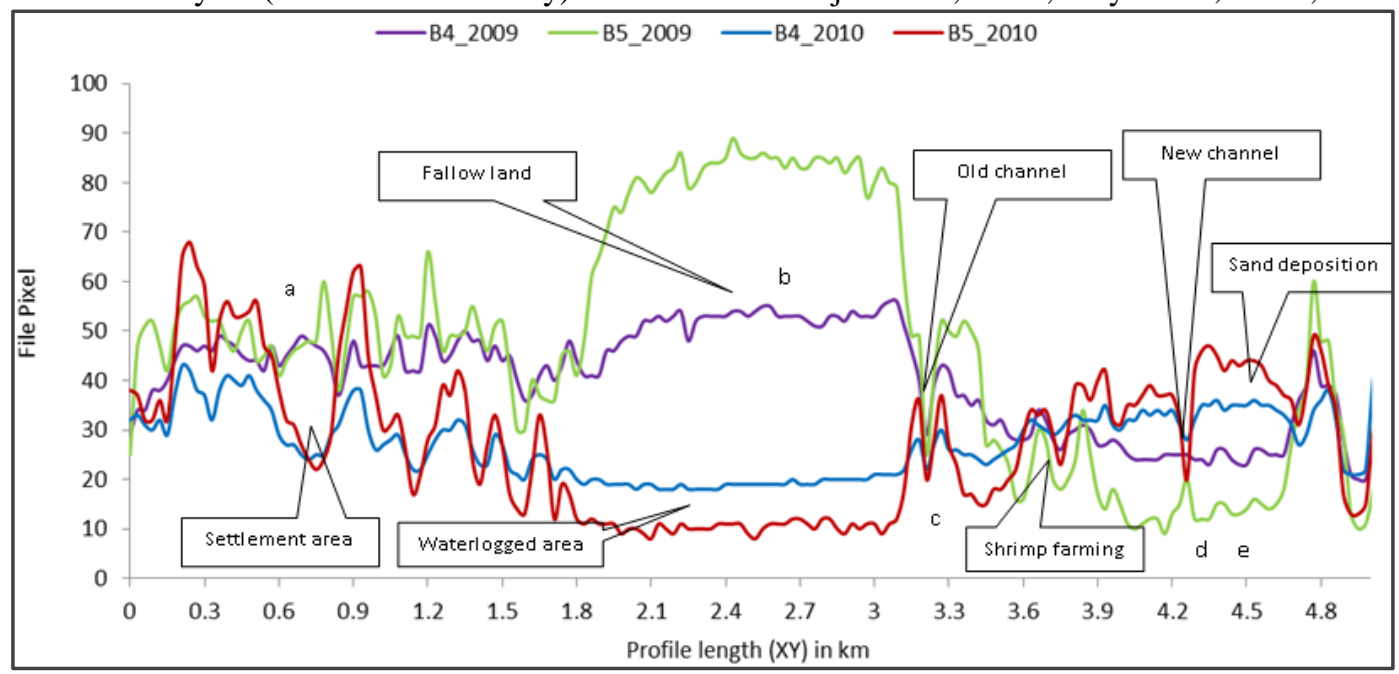

Fig. 20. Linear spatial profiles corresponding to three spectral bands $(5,4$, and 3$)$ of Landsat Tm spectral colour images on the two different dates 3 February, 2009 and 6 February, 2010 representing pre-Aila and post-Aila situation respectively in the Koyra upazila.

Referring to location ' $\mathrm{a}$ ' corresponding to settlement area in 2009 was affected by Cyclone Aila and presence of flood water is readily visible in 2010 after the cyclone Aila. Thus, the spectral value corresponding to position ' $a$ ' dropped down significantly in 2010 as compared to that in 2009 prior to the cyclone Aila. Location ' $b$ ' represents fallow land in 2009 with high reflectance value, while, the value significantly dropped down in 2010 due to water logging in the area causing high absorption of radiative value. Location 'c' represents the old channel in 2009 with low reflectance value, while, the value dropped down a little in 2010 due to water logging in the area causing more absorption of radiative value. Location ' $d$ ' represents new channel in 2010 with low reflectance value, while, the value in 2009 indicate presence of mixed environment of sand and water. Again, the increasing trend of radiative value represents sand deposition in 2010, while low radiative value in 2009 represents the possible presence of water over the area under study.

In this connection it may be mentioned that the Intergovernmental Panel on Climate Change (IPCC) AR4 notified about the future storm surges and related floods in Bangladesh with their thought that Bangladesh will likely to be more severe as future tropical cyclones
2010).

The cyclone affected area remained waterlogged for a considerable time period. The situation caused salinization of soil and inland water to certain level. As a result, agricultural activities in the region were under serious threat. The situation provoked acute scarcity of drinking water throughout the region.

\section{Conclusions}

Remote Sensing has made substantial contribution in disasters monitoring and damage assessment that leads the disaster management authorities to contribute significantly. In this paper, techniques for mapping disaster extent and assessing damages have been developed which can be served as a guideline for Remote Sensing (RS) and Geographical Information System (GIS) operations to improve the efficiency of flood disaster monitoring and management. Applicationoriented technical approach has been made that includes the development of necessary methodological framework based on a triangular technological initiative involving satellite based remote sensing (RS) coupled with appropriate ground RS technology platform and eventually guided by GPS-based positioning system. An 
object-oriented information layer taking into account various surface features has been generated using high resolution multiple satellite raster images. The complete setup with all the important intervening technical components has been encapsulated in GIS platform. Following spectral pattern recognition protocol in conjunction with spatial data analysis procedure has been utilized for targeted information retrieval. Digital image based spectral characterization of radiative response pattern of individual surface features in relation to feature specific radiative signature library under the information retrieval process has been employed. A GIS database with continuous updating option has been created and established to archive and update the RS retrieved surface parameters and information. The whole methodological operation including numerical and functional steps has been accomplished using a number of working platforms: the image-based operation involves Spatial Modeler Language (SML) in ERDAS Imagine in combination with GIS operation using ARC GIS. In addition,

The devastating cyclone Aila struck the south-western coastal region of Bangladesh and eastern coast of the neighboring West Bengal province of India at midday on 25 May 2009. Satkhira and Khulna were the worst hit districts, with nine other districts also badly affected. In the present work, technical approach has been made for assessing multiple damages caused in 2009 by tropical Cyclone Aila in Bangladesh using multi-sensor satellite imageries. Object based image classification techniques were applied for mapping cover categories corresponding to pre- and post-cyclone multi-sensor satellite imageries. Post classification change detection technique has been applied for characterization and identification of types of land cover changes. Analysis depicts that around 37,839 hectares area was flooded after cyclone hit. About $60 \%$ of the study area was significantly damaged by Aila. Near about 8,163 hectares of croplands were flooded by storm surges and with vegetation, settlements and infrastructure of the area all being completely or partially damaged.

Disaster management activities have to be a multidisciplinary and proactive approach. Remote sensing data and techniques along with GIS have proven their usefulness in disaster management plan especially in mapping the new situation after the disaster which helps in updating the geographical database. This can be used for the reconstruction of the damaged area. GIS helped to interpret information by creating satellite based thematic maps that show the spatial dimension of the affected areas. It has become easier to carry out the disaster management operations efficiently. Application of satellite imagery integrated with GIS help to identify areas that are disaster prone, zoning them according to risk magnitudes, inventory populations and assets at risk, and simulating damage scenarios. Remote sensing with GIS constitutes effective tools for monitoring and assessment of geospatial data and information for tropical cyclones monitoring, and damage assessment covering large land areas. These tools are even useful in managing disasters as they provide instant access to information required in management decisions.

\section{Acknowledgements}

The authors are thankful to the Chairman, Bangladesh Space Research and Remote Sensing Organization (SPARRSO). One of the authors Dr. Sajidur RAHMAN is thankful to the Director of Centre for Climate Change and Environmental Research (C3ER), BRAC University, Dhaka, Bangladesh for permitting to carry out and publish this research work.

\section{References}

Ahmed, B., Kelman, I., Fehr, H.K., Saha, M. (2016). Community Resilience to Cyclone Disasters in Coastal Bangladesh. Sustainability 8, 805.

Anwar Ali, Dewan Abdul Quadir, Abdul Mannan Sardar, Hafizur Rahman, A.Z.MD. Zahedul Islam and Abdus Shahid (1998). Flood Monitoring and Damage Assessment in Bangladesh Using RADARSAT Data. RADARSAT International, ADRO Symposium, Montreal, Canada, 13-15 October, 1998.

BBS (2012a). Population and Housing Census 2011. Community Report Satkhira Zila. Bangladesh Bureau of Statistics, Dhaka.

BBS (2012b). Population and housing census 2011. Community Report Khulna. Bangladesh Bureau of Statistics, Dhaka.

Bishawjit Mallick, Bayes Ahmed, Joachim Vogt (2017), Living with the Risks of Cyclone Disasters in the South-Western Coastal Region of Bangladesh. Environments 2017, 4, 13; doi:10.3390/ environments4010013.

Dewan, A. M., Yamaguchi, Y. (2009). Land use and land cover change in Greater Dhaka, Bangladesh: Using remote sensing to promote sustainable urbanization. Applied Geography, 29 (3), 390-401.

Government of Bangladesh (GoB) (2005). Unlocking the potential: national strategy for accelerated poverty reduction. Dhaka, General Economic Division, Planning Commission, Government of the People's Republic of Bangladesh.

Howarth, P.J., G. M. Wickware (1981). Procedures for Change Detection Using Landsat Digital Data. International Journal of Remote Sensing. 2(3): 277291. doi:10.1080/01431168108948362.

IPCC, 2007, Impacts, Adaptation and Vulnerability: Summary for Policymakers. Working Group II Contribution to the Intergovernmental Panel on Climate Change Fourth Assessment Report. IPCC, Geneva.

Islam, M. S. (2001). Sea-level changes in Bangladesh: The last ten thousand years, Asiatic Society of Bangladesh.

Kreft, S., Eckstein, D., Melchior, I. (2016). Global Climate Risk Index 2017, German watch. Bonn

Kumar, U., Baten, M.A., Masud, A., Osman, K.S., Rahman, M.M. (2010), Cyclone Aila: One Year on Natural Disasterto Human Sufferings. Khulna, Bangladesh: Unnayan Onneshan - Humanity Watch - Nijera Kori. 
Li, X., Yeh, AGO (1998). 'Principal component analysis of stacked multi-temporal images for monitoring of rapid urban expansion in the Pearl River Delta', International Journal of Remote sensing,. 19(8): 1501-1518.

Lopez, E., Bocco, G (2001). Predicting land-cover and land use change in the urban fringe: a case in Morelia city, Mexico', Landscape and urban planning, 55: 271-285

Lu, D., P. Mausel, E. Brondízio., E. Moran, (2004). Change detection techniques. International Journal of Remote Sensing, 25, Issue 12, 2365-2401.

Mahmuduzzaman, Md., Zahir Uddin Ahmed, A. K. M. Nuruzzaman, Fazle Rabbi Sadeque Ahmed, (2014). Causes of Salinity Intrusion in Coastal Belt of Bangladesh. International Journal of Plant Research, 4, 8-13.

Mas, J.-F. (1999). Monitoring land-cover changes: a com parison of change detection techniques International Journal of Remote Sensing, 1999, vol. 20, No. 1, 139-152.

Menteş, E. N. , Kaya, Ş., Tanık, A. and Gazioğlu, C. (2019). Calculation of Flood Risk Index for Yesilirmak Basin-Turkey, International Journal of Environment and Geoinformatics, 6(3), 288-299, doi.10.30897/ijegeo.661533

MWR (2005) Coastal zone policy vol Dhaka. Government of Bangladesh.

MWR (2005). Coastal Zone Policy. Ministry of Water Resources (MWR), Dhaka, Bangladesh.

Myint, S.W., M. Yuan, R. S. Cerveny, C. Giri (2008). Categorizing natural disaster damage assessment using satellite-based geospatial techniques. Nat. Hazards Earth Syst. Sci., 8, 707-719.

Nelson, R. F. (1983). Detecting forest canopy change due to insect activity using Landsat MSS. Photogrammetric Engineering and Remote Sensing, 9, 1303-1314

Phinn, S.R. (1998). A framework for selecting appropriate remotely sensed data dimensions for environmental monitoring and management. International Journal of Remote Sensing 19:34573463

Pilon, P. G., Howarth, P. J., Bullock, R. A. (1988). An enhanced classification approach to change detection in semi-arid environments. Photogrammetric Engineering and Remote Sensing, 12, 1709-1716.

Prenzel, B. (2004). Remote sensing-based quantification of land-cover and land-use change for planning, Progress in planning, 61: 281-299.

Rahman, H. (1999). Study of the catastrophic flood of 1998 in Bangladesh using multitemporal Radarsat Scansar data. Proceedings of the Second International Symposium on Operationalization of Remote Sensing organized by the International Institute for Aerospace Survey and Earth Sciences (ITC), Netherlands, August 16-20, 1999.

Rahman, H., G. Dedieu (1994). SMAC: A Simplified Method for the Atmospheric Correction of Satellite Measurements in the Solar Spectrum. International Journal of Remote Sensing, 15, 123-143.
Rahman, S., Rahman, H. (2022). Study on the Aridity in the North-Western (NW) Part of Bangladesh through Combined Application of Remote Sensing, GIS and Geophysical Data, International Journal of Environment and Geoinformatics, 9(1), 79-96.

Rowsell, E.C.P., Sultana, P., Thompson, P. (2013). The 'last resort' Population movement in response to climate-related hazards in Bangladesh. Environ Sci Policy 27: S44-S59

Roy, K., Kumar, U., Mehedi, H., Sultana, T., Ershad, D. M. (2009). Initial damage assessment report of cyclone Aila with focus on Khulna district. Khulna, Bangladesh: Unnayan Onneshan - Humanity Watch - Nijera Kori.

Sharma, A. K., Varun, J., Kumar, K. (2010). Use of remote sensing and GIS in disaster management in Gangtok area. Sikkim Article.

Shinozuka, M., Rejaie, A. (2000). Correlational analysis of remotely sensed pre- and post-disaster images. SPIE's 7th Annual International Symposium on Smart Structures and Materials.

Singh, Ashbindu (1989). Review Article Digitalchange detection techniques using remotely-sensed data. International Journal of Remote Sensing, 10(6): 989-1003.

Stryker, T., Jones, B. (2009), Disaster response and the international charter program.

Sultana, N. , Rahman, H. , Sharifee, M. N. H. , Faisal, B. R., Ahmed, M. T. (2019). Study on the Effects of Landcover Changes on Surface Albedo and Surface Temperature in Bangladesh Using Remote Sensing and GIS, International Journal of Environment and Geoinformatics, 6(3), 277-287, doi.10.30897 /ijegeo.546032

UNEP (2001). Bangladesh state of the environment. United Nations Development Programmes (UNEP), Thailand.

USAID (2015). Bangladesh: Cyclone Fact Sheet \#1 (FY 2009)..

Visser, S.J., Dawood, A.S. (2004). Real-time natural disasters detection and monitoring from smart earth observation satellite, Journal of Aerospace Engineering, 17: 10-19.

Wang, F., Xu, J.Y. (2010). Comparison of Remote Sensing Change Detection Techniques for Assessing Hurricane Damage to Forest. Environmental Monitoring and Assessment, 162, 311-326 (2010). 